\title{
Dimeric Tetrahydroanthracene Regioisomers and Their Monomeric Precursor Produced by Streptomyces fumigatiscleroticus HDN10255
}

Junxiao Wang, ${ }^{{ }^{\dagger}}$ Haotian Wang, ${ }^{{ }_{\dagger}}{ }^{\infty}$ Chunxiao Sun, ${ }^{\dagger}$ Fenge Li,,${ }^{\dagger}$ Yingqiang Wu,${ }^{\dagger}$ Guojian Zhang, ${ }^{\dagger \dagger}$ Qianqun Gu, ${ }^{\dagger}$ Tianjiao Zhu, $^{\dagger}$ Dehai Li, ${ }^{\dagger+}$ and Qian Che ${ }^{* \dagger}$

${ }^{\dagger}$ School of Medicine and Pharmacy, Ocean University of China, Qingdao 266003, People's Republic of China

Laboratory for Marine Drugs and Bioproducts of Qingdao National Laboratory for Marine Science and Technology, Qingdao, 266237, People's Republic of China

${ }^{\S}$ Faculty of Pharmacy, Bengbu Medical College, Bengbu, 233030

${ }^{\perp}$ The authors contributed equally to this paper 


\section{List of supporting information}

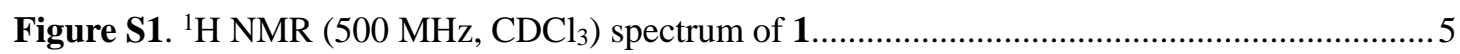

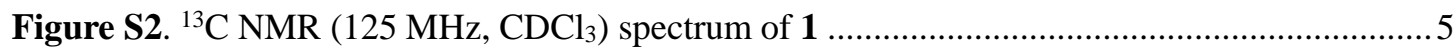

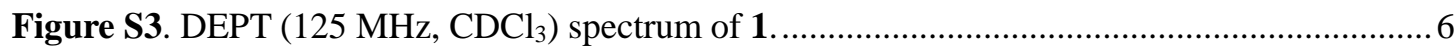

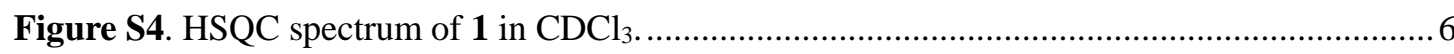

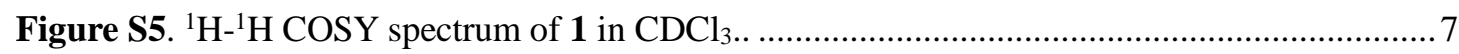

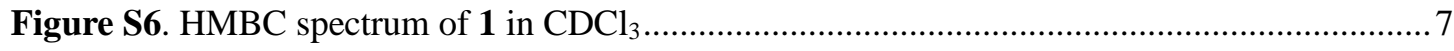

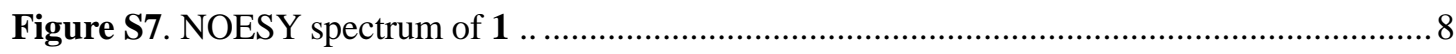

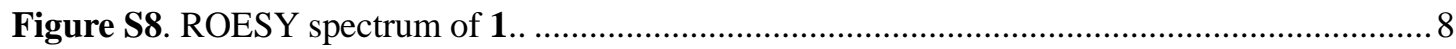

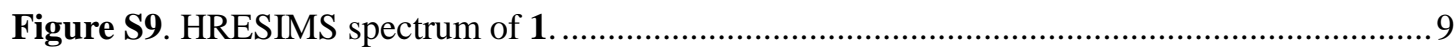

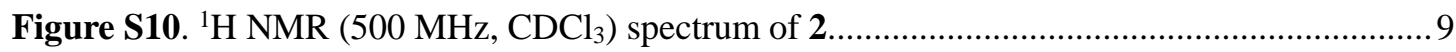

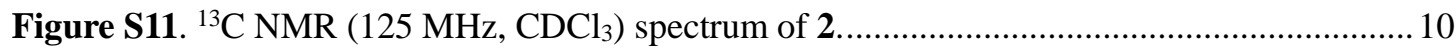

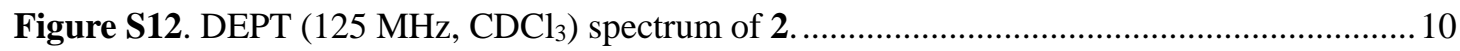

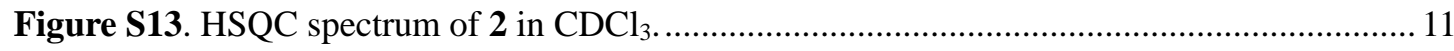

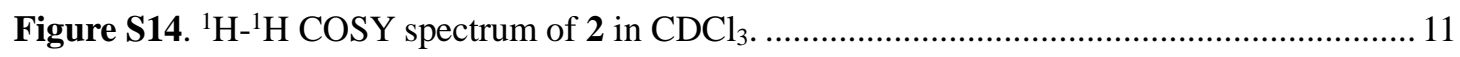

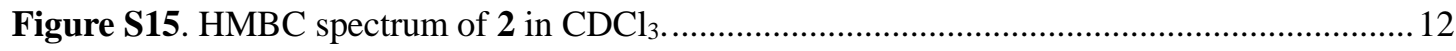

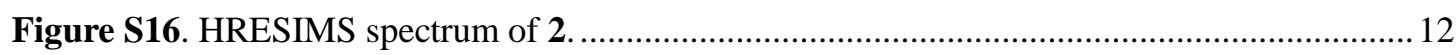

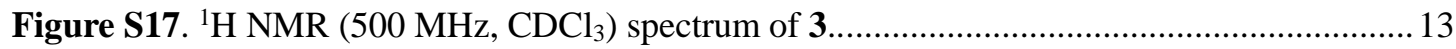

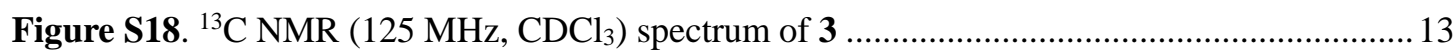

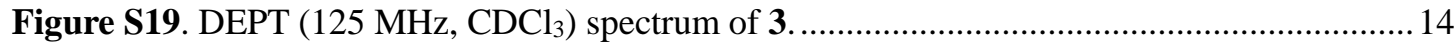

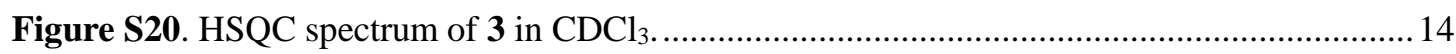

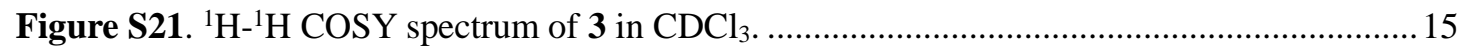

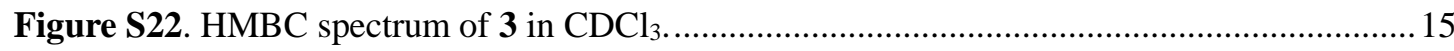

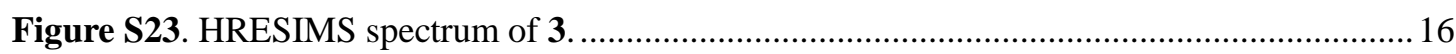

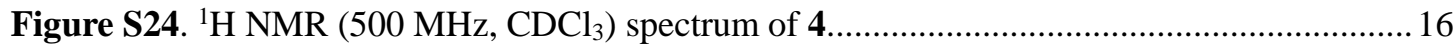

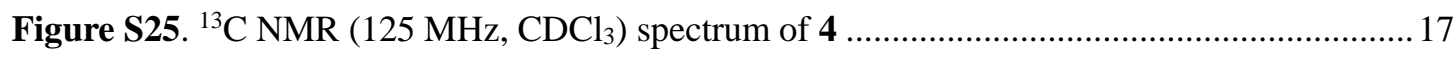

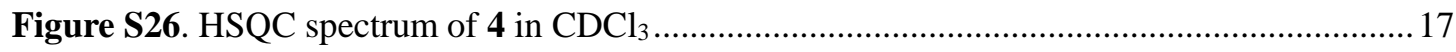

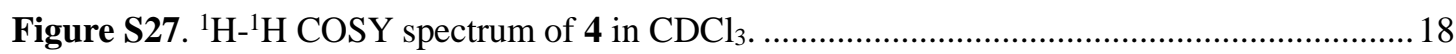

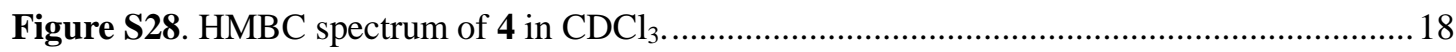


Figure S29. HRESIMS spectrum of 4 .

Figure S30 ${ }^{1} \mathrm{H}$ NMR $\left(500 \mathrm{MHz}, \mathrm{CDCl}_{3}\right)$ spectrum of $\mathbf{5}$

Figure S31. ${ }^{13} \mathrm{C}$ NMR $\left(125 \mathrm{MHz}, \mathrm{CDCl}_{3}\right)$ spectrum of 5

Figure S32. DEPT (125 MHz, $\left.\mathrm{CDCl}_{3}\right)$ spectrum of 5.

Figure S33. HSQC spectrum of 5 in $\mathrm{CDCl}_{3}$

Figure S34. ${ }^{1} \mathrm{H}-{ }^{1} \mathrm{H}$ COSY spectrum of 5 in $\mathrm{CDCl}_{3}$.

Figure S35. HMBC spectrum of 5 in $\mathrm{CDCl}_{3}$ 22

Figure S36. HRESIMS spectrum of $\mathbf{5}$. 22

Figure S37. HMBC correlations of compounds 1-5. 23

Figure S38. Key NOESY and ROESY correlations of compound 1. 23

Figure S39. ${ }^{1} \mathrm{H}$ NMR (400 MHz, acetone- $d_{6}$ ) spectrum of $\mathbf{1}$. 24

Figure S40. ${ }^{13} \mathrm{C}$ NMR (100 MHz, acetone- $\left.d_{6}\right)$ spectrum of 1. 24

Figure S41. HPLC analysis $(420 \mathrm{~nm})$ between compound 1 and julichrome $\mathrm{Q}_{10}$. 25

Figure S42.Correlation plots of experimental ${ }^{1} \mathrm{H}$ and ${ }^{13} \mathrm{C}$ NMR chemical shifts versus the corresponding calculated data for $(3 S, 4 R)-\mathbf{1}(\mathbf{1 a})$ and $(3 S, 4 S)-\mathbf{1}(\mathbf{1 b})$ 25

Figure S43. Comparison of experimental ECD spectrum of 2 with calculated ECD spectra of $(P$, $\left.3 S, 4 S, 3^{\prime} S, 4 ' S\right)-\mathbf{2}(\mathbf{2 a})$ versus $\left(M, 3 S, 4 S, 3^{\prime} S, 4 ' S\right)-\mathbf{2}(\mathbf{2 b})$ and $\left(P, 3 R, 4 R, 3^{\prime} R, 4^{\prime} R\right)$-2 (2c) versus $\left(M, 3 R, 4 R, 3^{\prime} R, 4^{\prime} R\right)-2(\mathbf{2 d})$ 26

Figure S44. Comparison of experimental ECD spectrum of 4 with calculated ECD spectra of $(P$, 3S, 4S, 3'S, 4'S)-4 (4a) versus $\left(M, 3 S, 4 S, 3^{\prime} S, 4^{\prime} S\right)-\mathbf{4}(\mathbf{4 b})$ and $\left(P, 3 R, 4 R, 3^{\prime} R, 4^{\prime} R\right)-\mathbf{4}$ (4c) versus $\left(M, 3 R, 4 R, 3^{\prime} R, 4^{\prime} R\right)-4(4 \mathbf{d})$. 26

Figure S45. Comparison of experimental ECD spectrum of 5 with calculated ECD spectra of $(P$, $\left.3 S, 4 S, 3^{\prime} S, 4^{\prime} S\right)-\mathbf{5}(\mathbf{5 a})$ versus $\left(M, 3 S, 4 S, 3^{\prime} S, 4^{\prime} S\right)-\mathbf{5}(\mathbf{5 b})$ and $\left(P, 3 R, 4 R, 3^{\prime} R, 4^{\prime} R\right)-\mathbf{5}(\mathbf{5} \mathbf{c})$ versus $\left(M, 3 R, 4 R, 3^{\prime} R, 4^{\prime} R\right)-5(5 \mathbf{d}) .$.

Figure S46. HPLC analysis (350 nm) of compounds $\mathbf{1 - 5}$ from the crude of HDN10255... 27

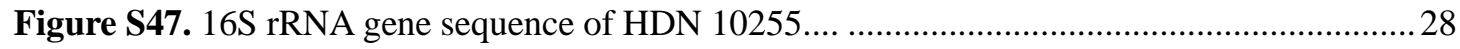

Figure S48. IR spectra of compounds 1-5...... 29

Table S1. Calculated and experimental values for ${ }^{1} \mathrm{H}$ NMR chemical of $\mathbf{1 a}$. 30

Table S2. Calculated and experimental values for ${ }^{1} \mathrm{H}$ NMR chemical of 1 c... 31

Table S3. Calculated and experimental values for ${ }^{13} \mathrm{C}$ NMR chemical of $\mathbf{1 a}$ 31 
Table S4. Calculated and experimental values for ${ }^{13} \mathrm{C}$ NMR chemical of 1c.

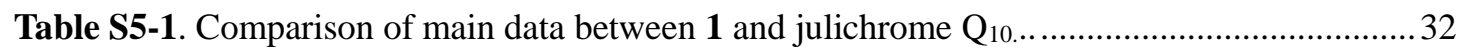

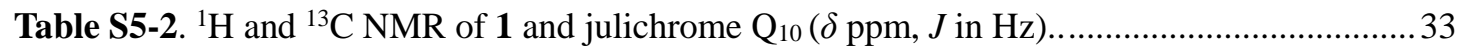


Figure S1. ${ }^{1} \mathrm{H}$ NMR (500 MHz, $\left.\mathrm{CDCl}_{3}\right)$ spectrum of $\mathbf{1}$.

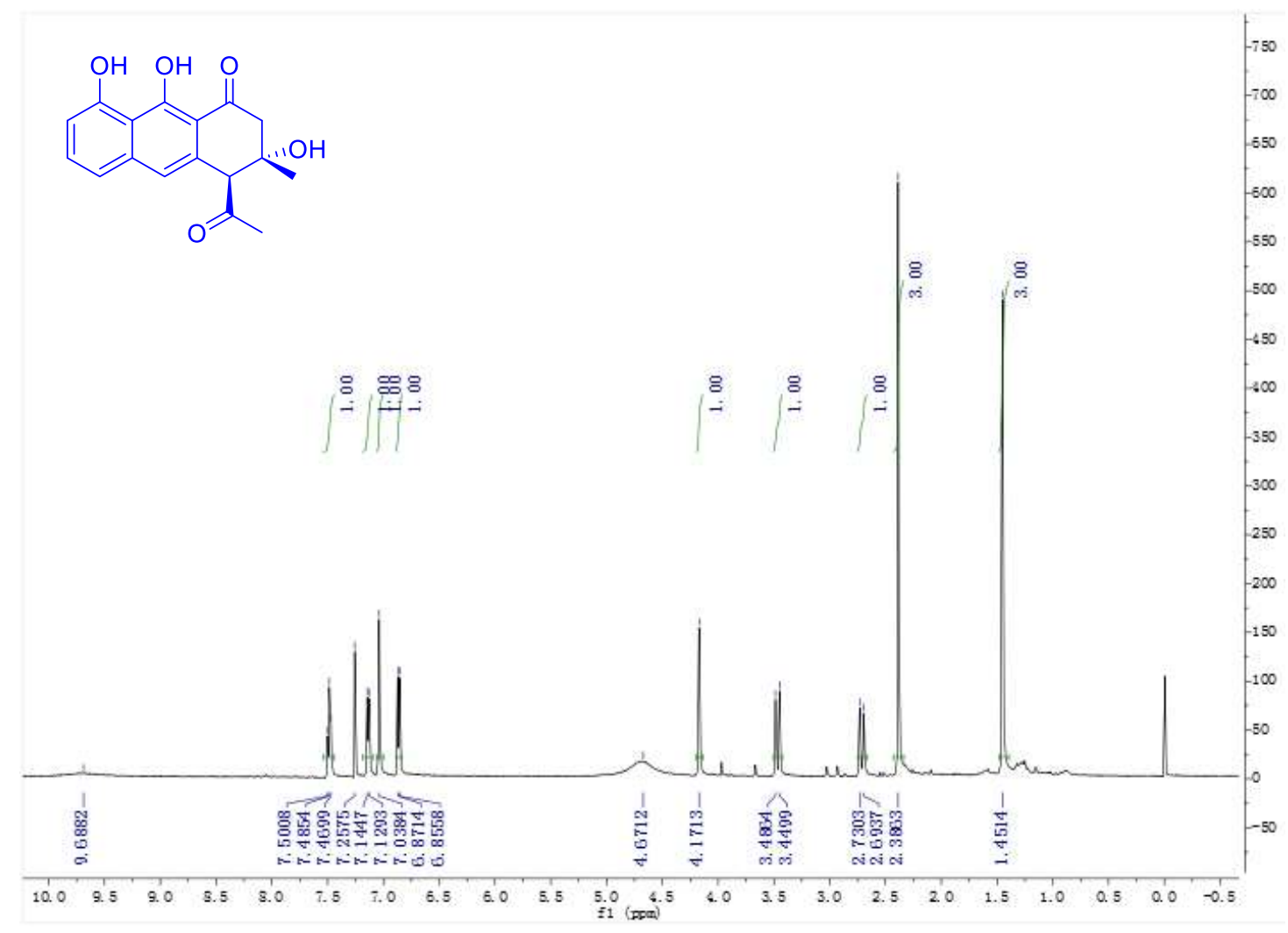

Figure S2. ${ }^{13} \mathrm{C}$ NMR $\left(125 \mathrm{MHz}, \mathrm{CDCl}_{3}\right)$ spectrum of $\mathbf{1}$.

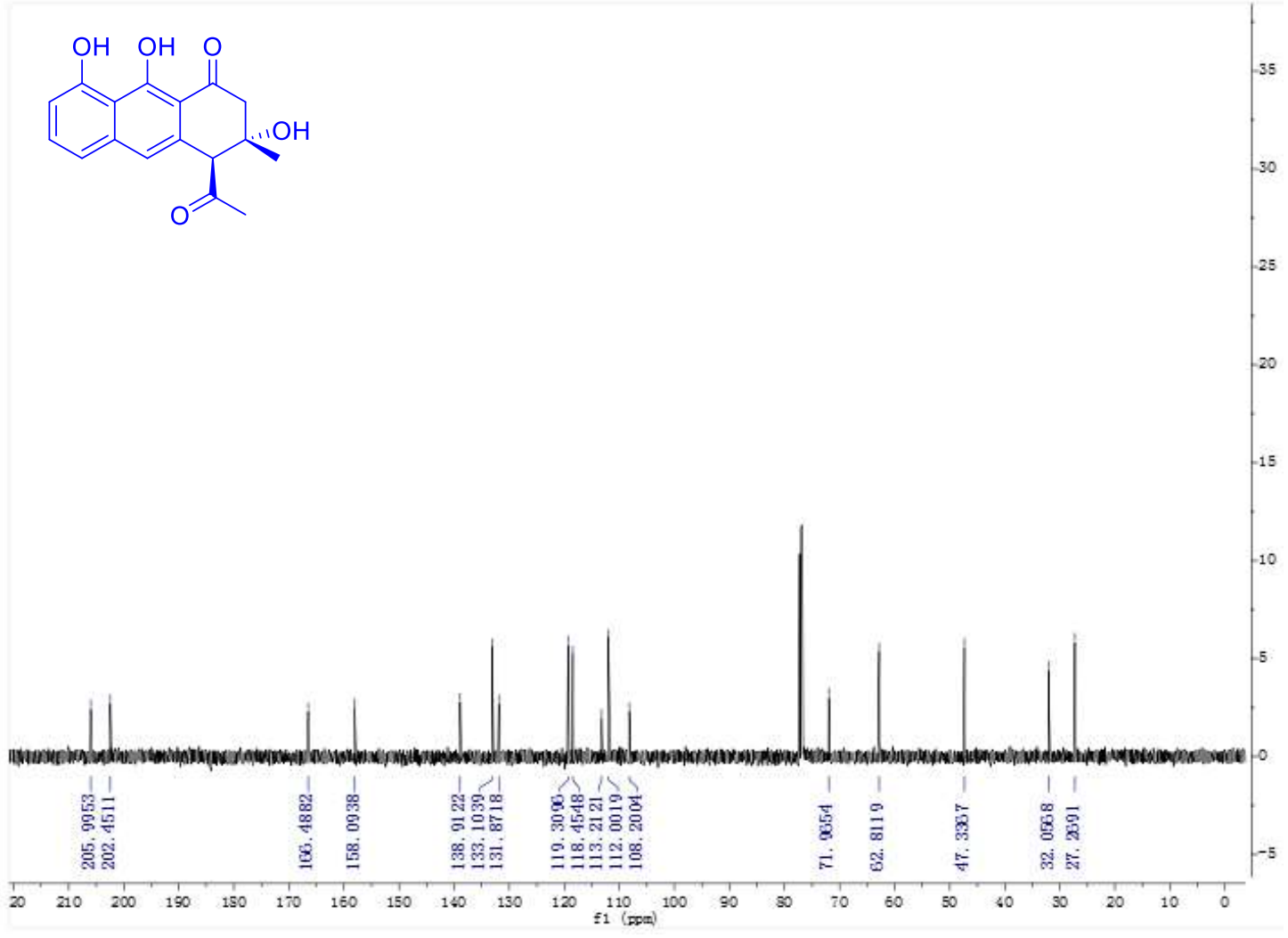

5 
Figure S3. DEPT (125 MHz, $\mathrm{CDCl}_{3}$ ) spectrum of $\mathbf{1}$.<smiles>CC(=O)C1c2cc3cccc(O)c3c(O)c2C(=O)C[C@H]1O</smiles>

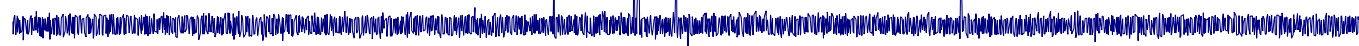
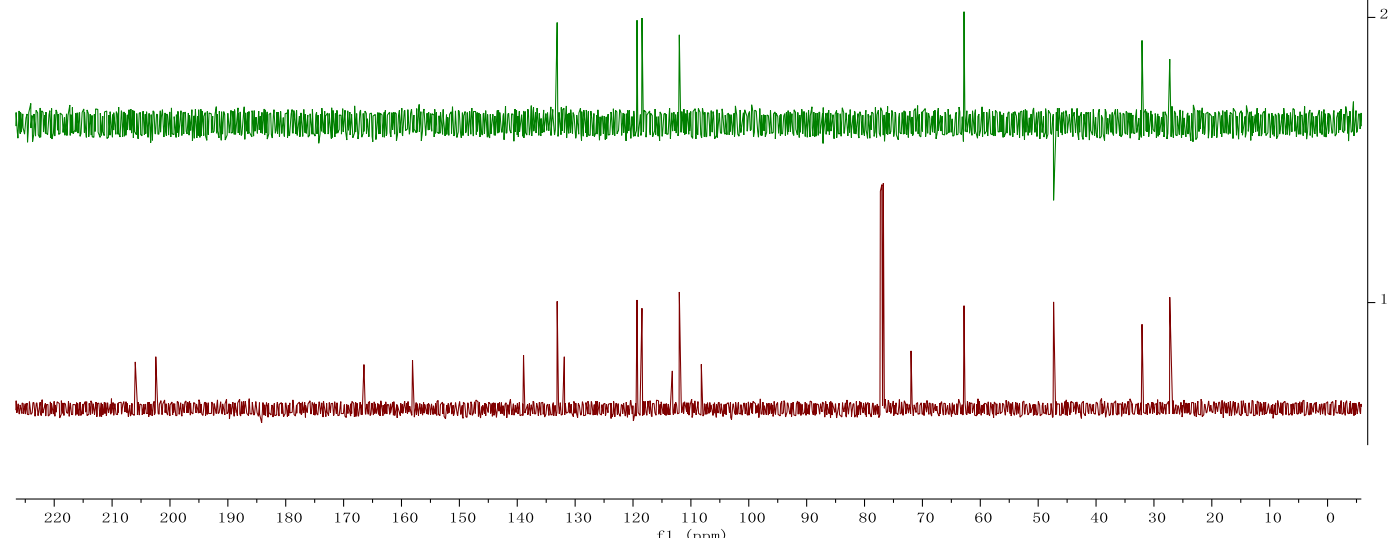

Figure S4. $\mathrm{HSQC}$ spectrum of $\mathbf{1}$ in $\mathrm{CDCl}_{3}$.

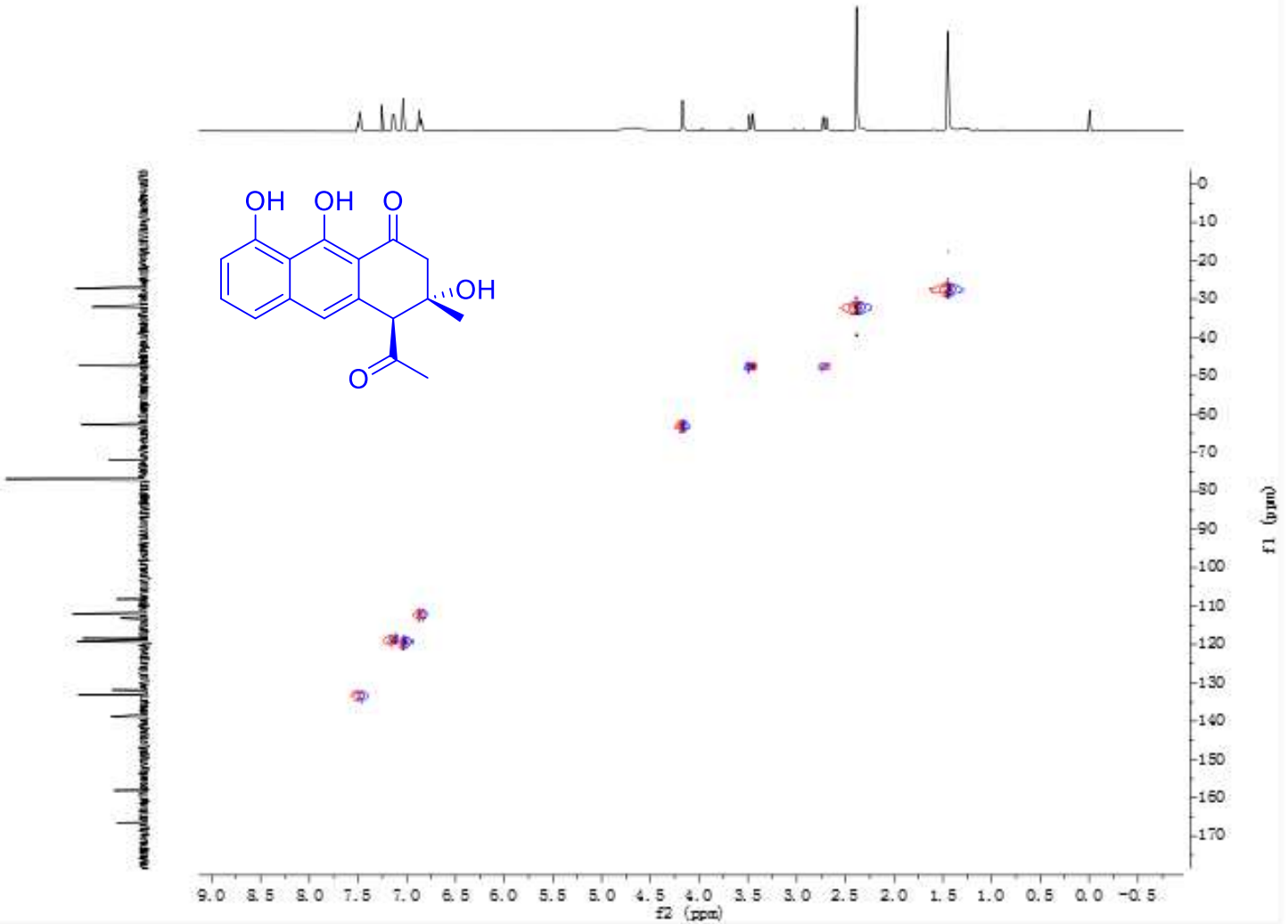


Figure S5. ${ }^{1} \mathrm{H}-{ }^{1} \mathrm{H}$ COSY spectrum of $\mathbf{1}$ in $\mathrm{CDCl}_{3}$.

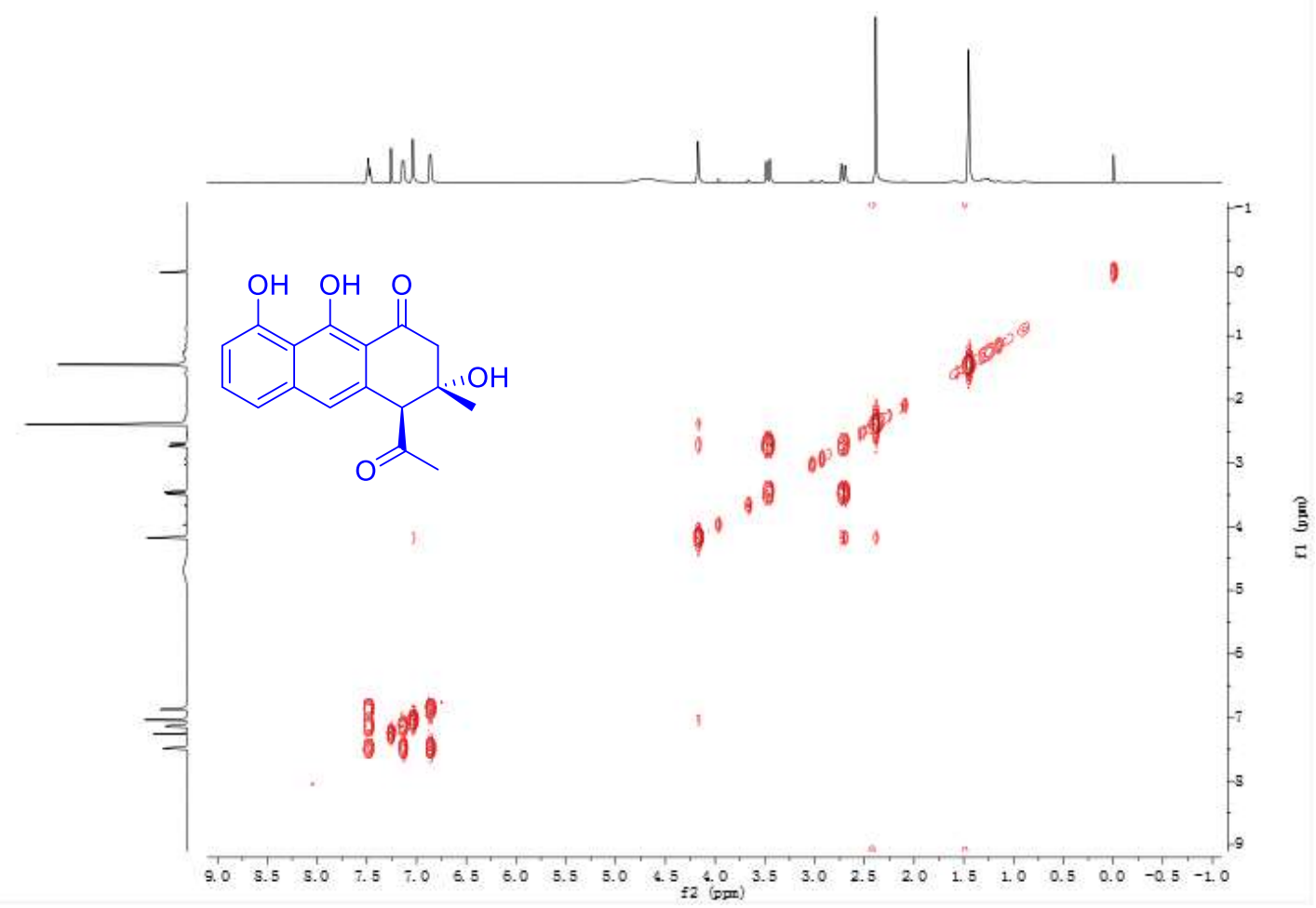

Figure S6. $\mathrm{HMBC}$ spectrum of $\mathbf{1}$ in $\mathrm{CDCl}_{3}$.

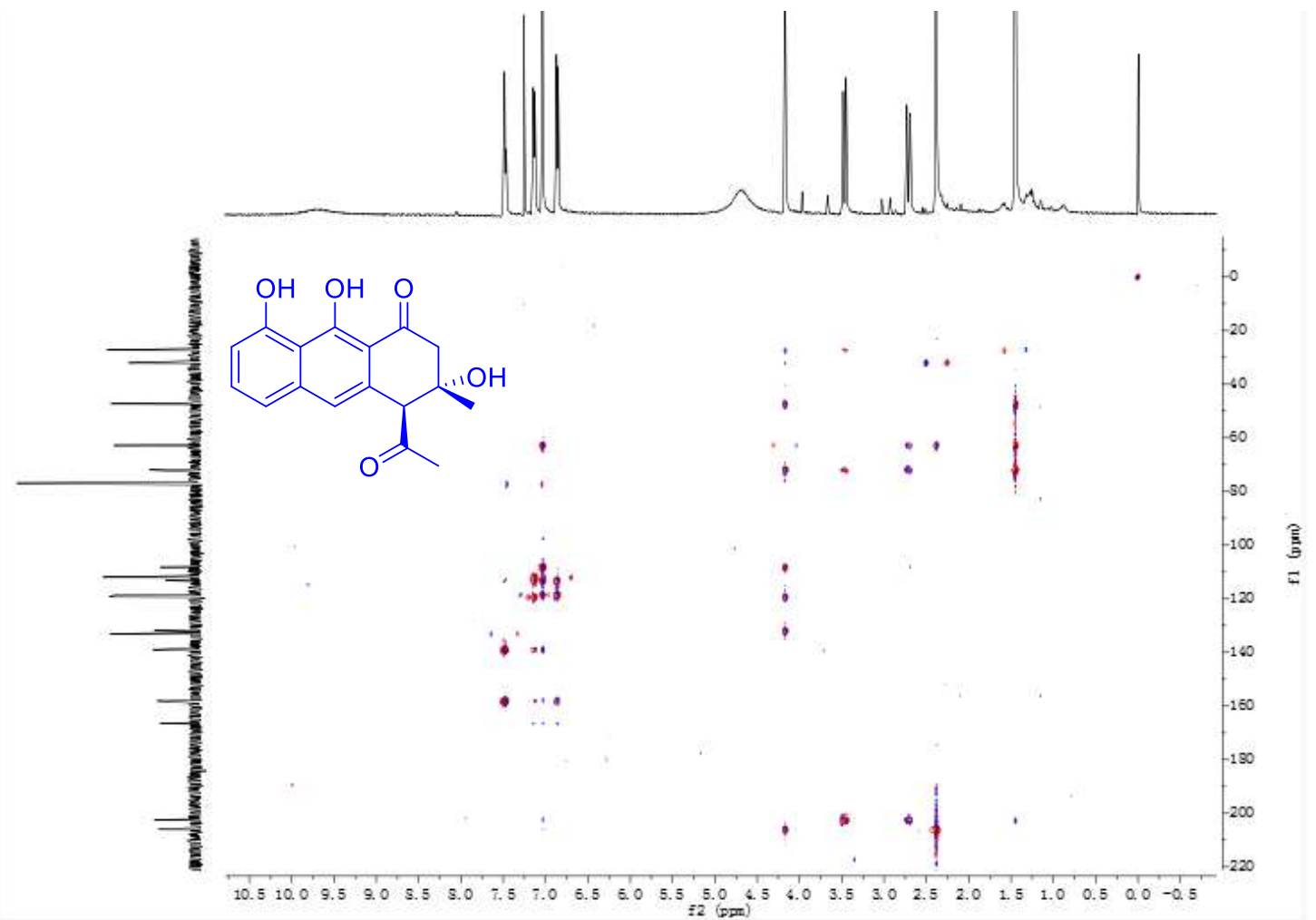


Figure S7. NOESY spectrum of $\mathbf{1}$ in $\mathrm{CDCl}_{3}$.

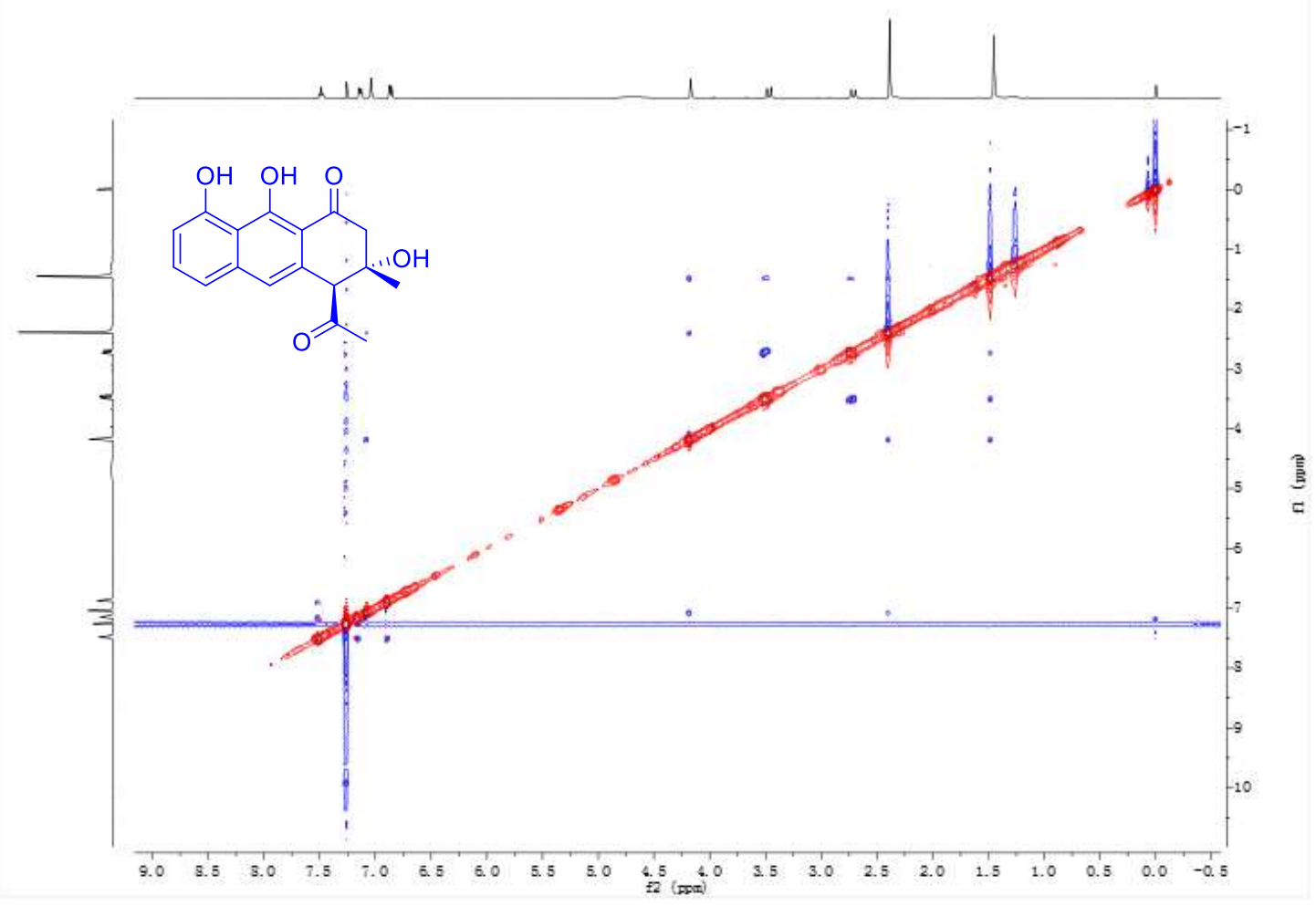

Figure S8. ROESY spectrum of $\mathbf{1}$ in $\mathrm{CDCl}_{3}$.

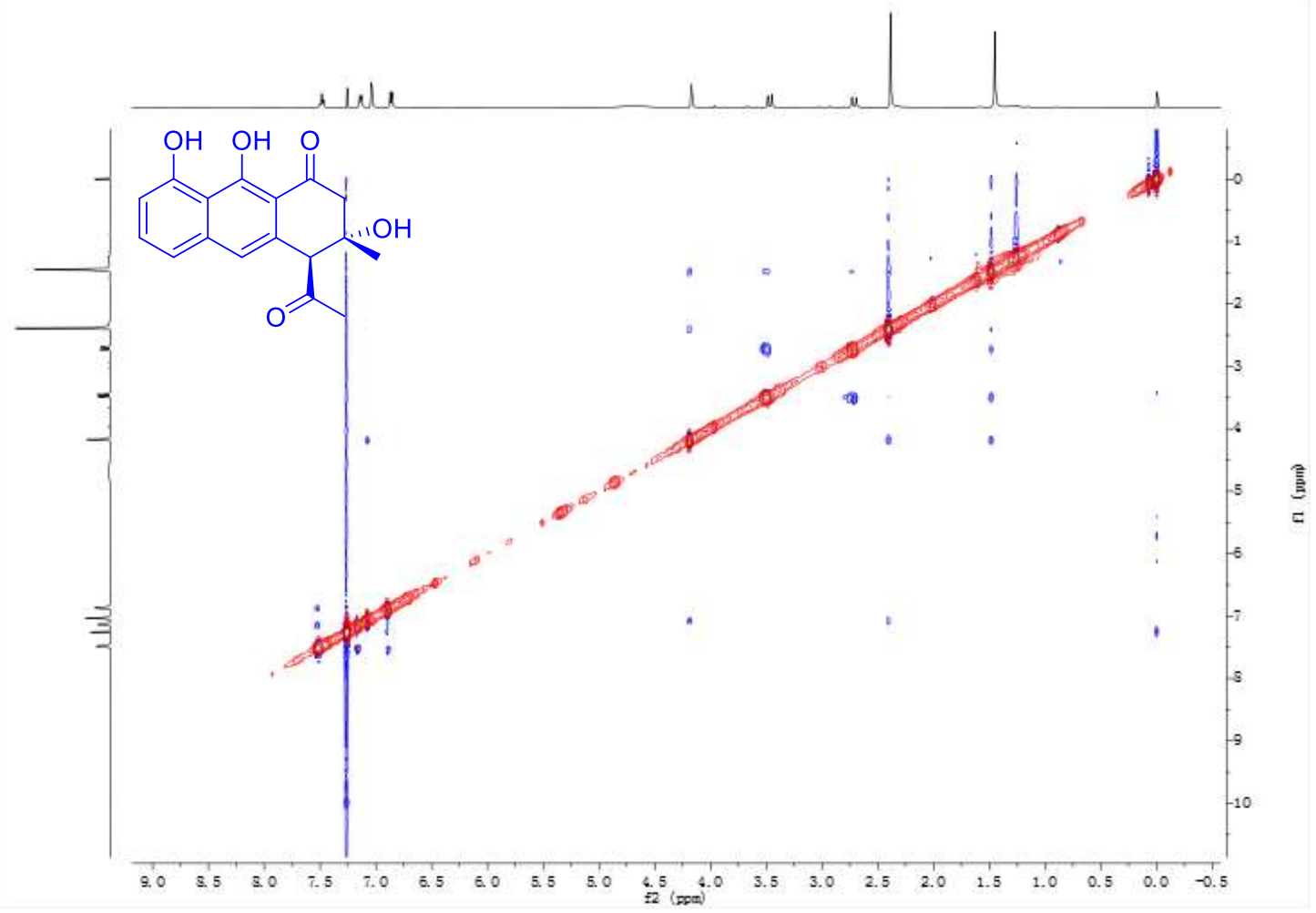


Figure S9. HRESIMS spectrum of $\mathbf{1}$.

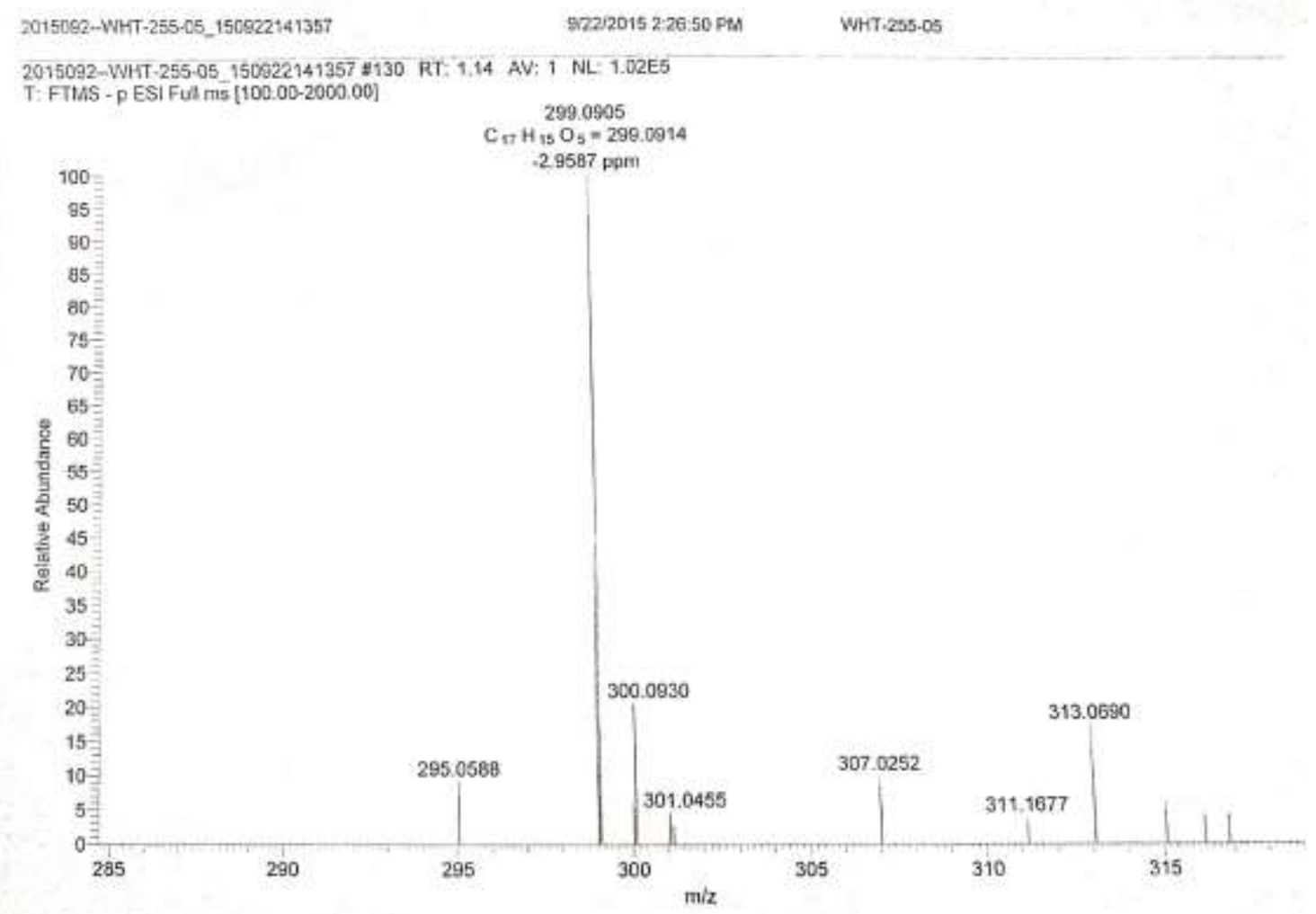

Figure S10. ${ }^{1} \mathrm{H}$ NMR $\left(500 \mathrm{MHz}, \mathrm{CDCl}_{3}\right)$ spectrum of 2.

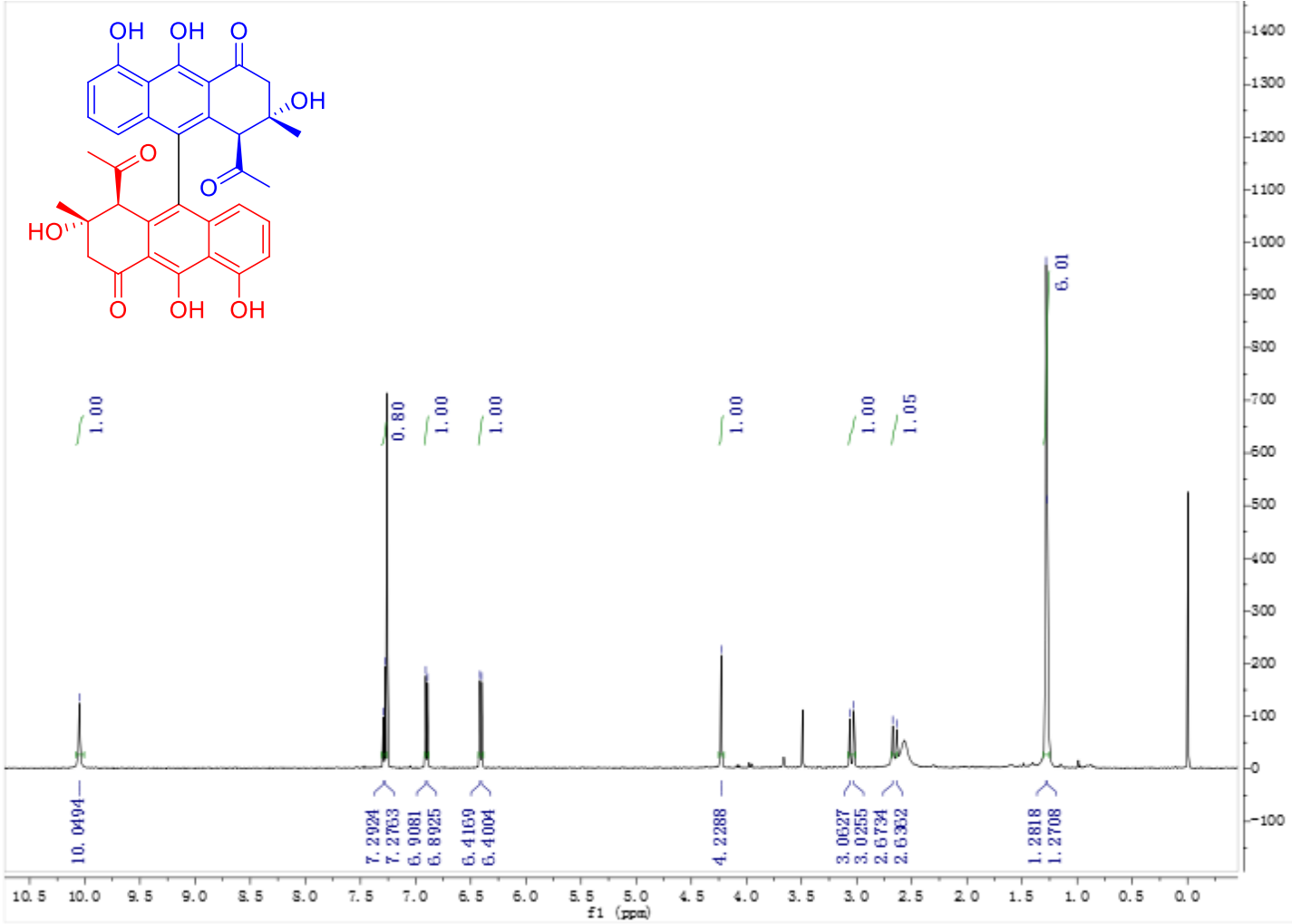


Figure S11. ${ }^{13} \mathrm{C}$ NMR $\left(125 \mathrm{MHz}, \mathrm{CDCl}_{3}\right)$ spectrum of 2.

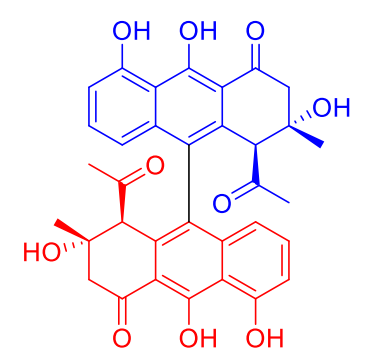

Figure S12. DEPT (125 MHz, $\left.\mathrm{CDCl}_{3}\right)$ spectrum of 2.
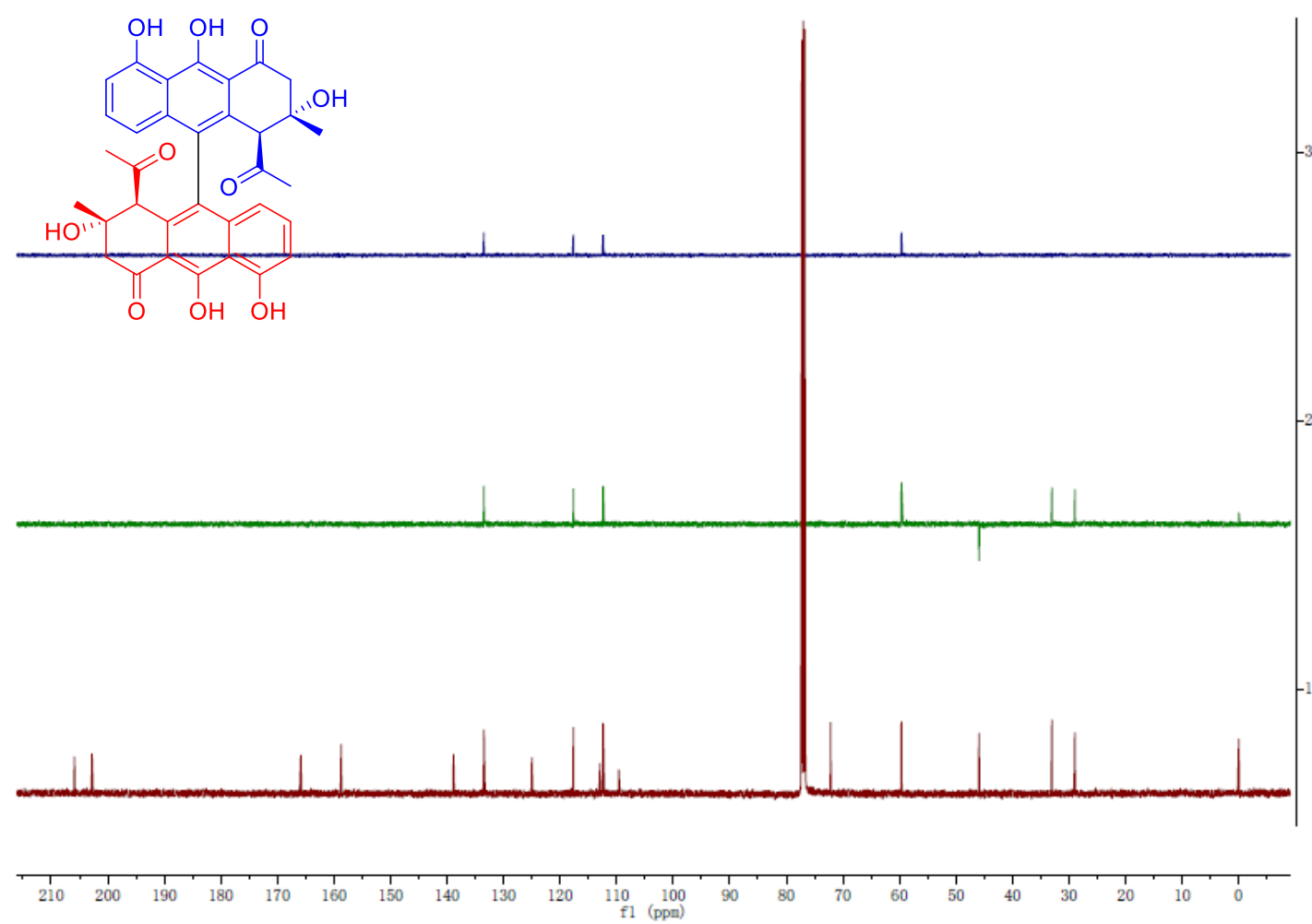
Figure S13. HSQC spectrum of $\mathbf{2}$ in $\mathrm{CDCl}_{3}$.

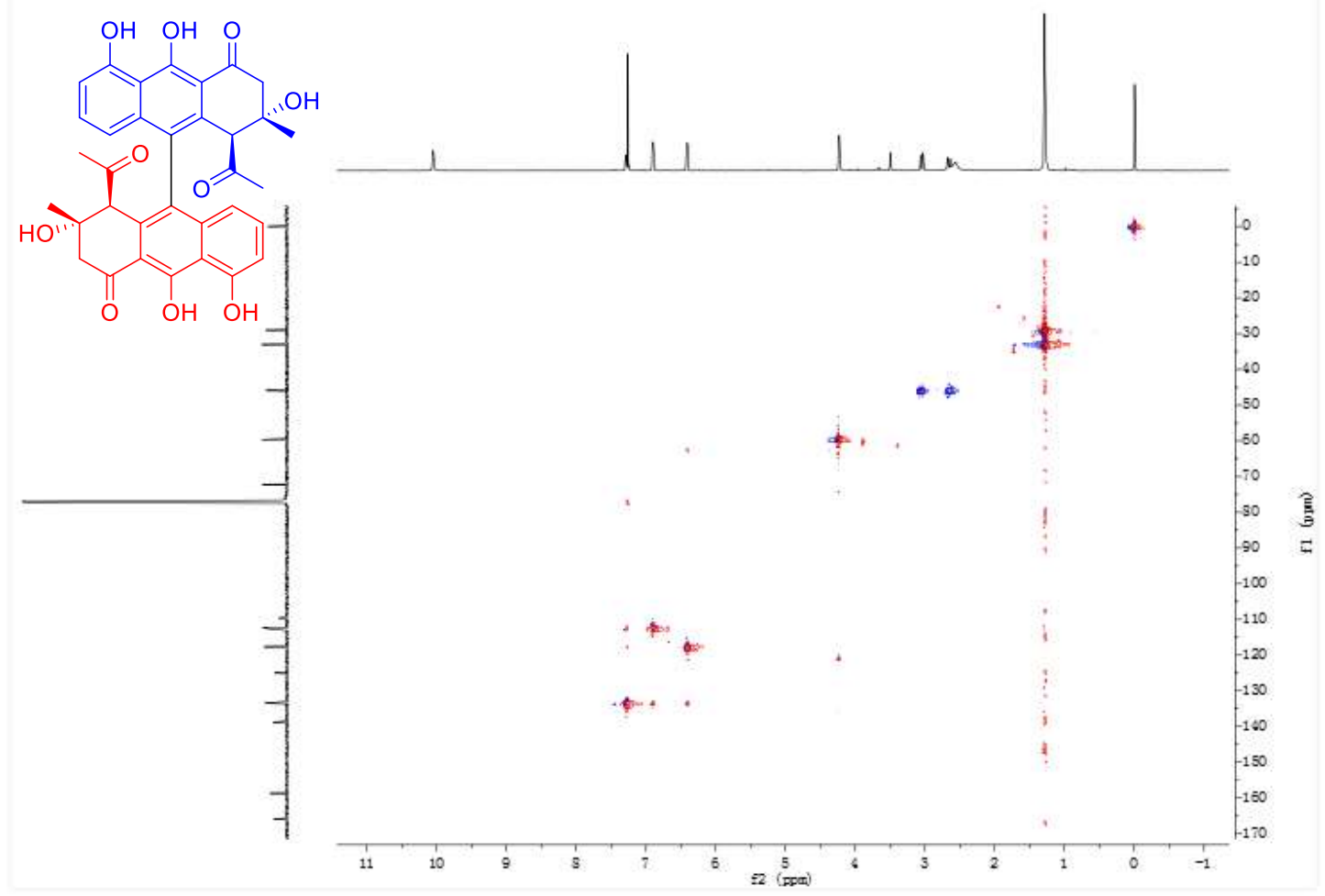

Figure S14. ${ }^{1} \mathrm{H}-{ }^{1} \mathrm{H}$ COSY spectrum of 2 in $\mathrm{CDCl}_{3}$.

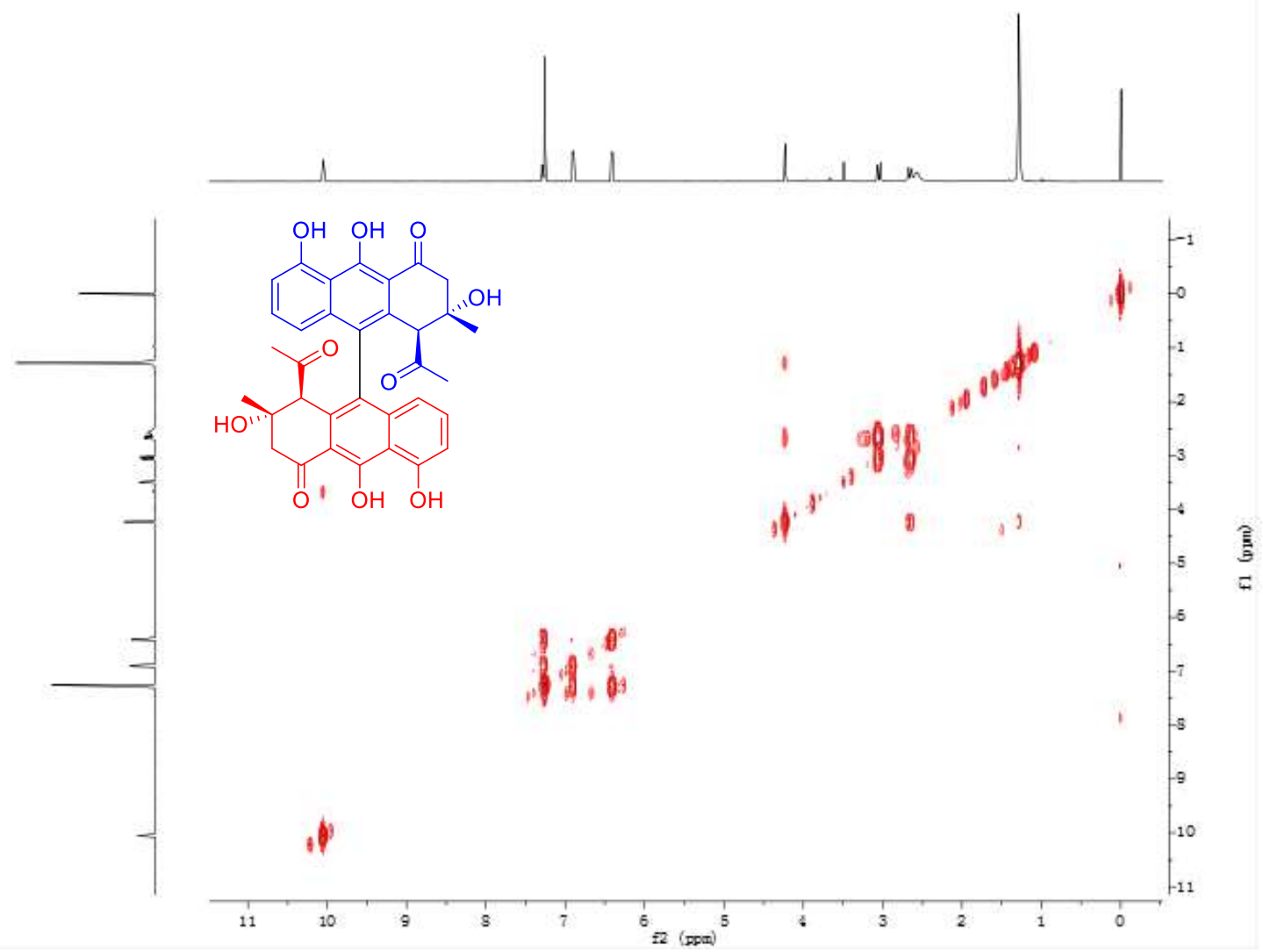


Figure S15. $\mathrm{HMBC}$ spectrum of $\mathbf{2}$ in $\mathrm{CDCl}_{3}$.

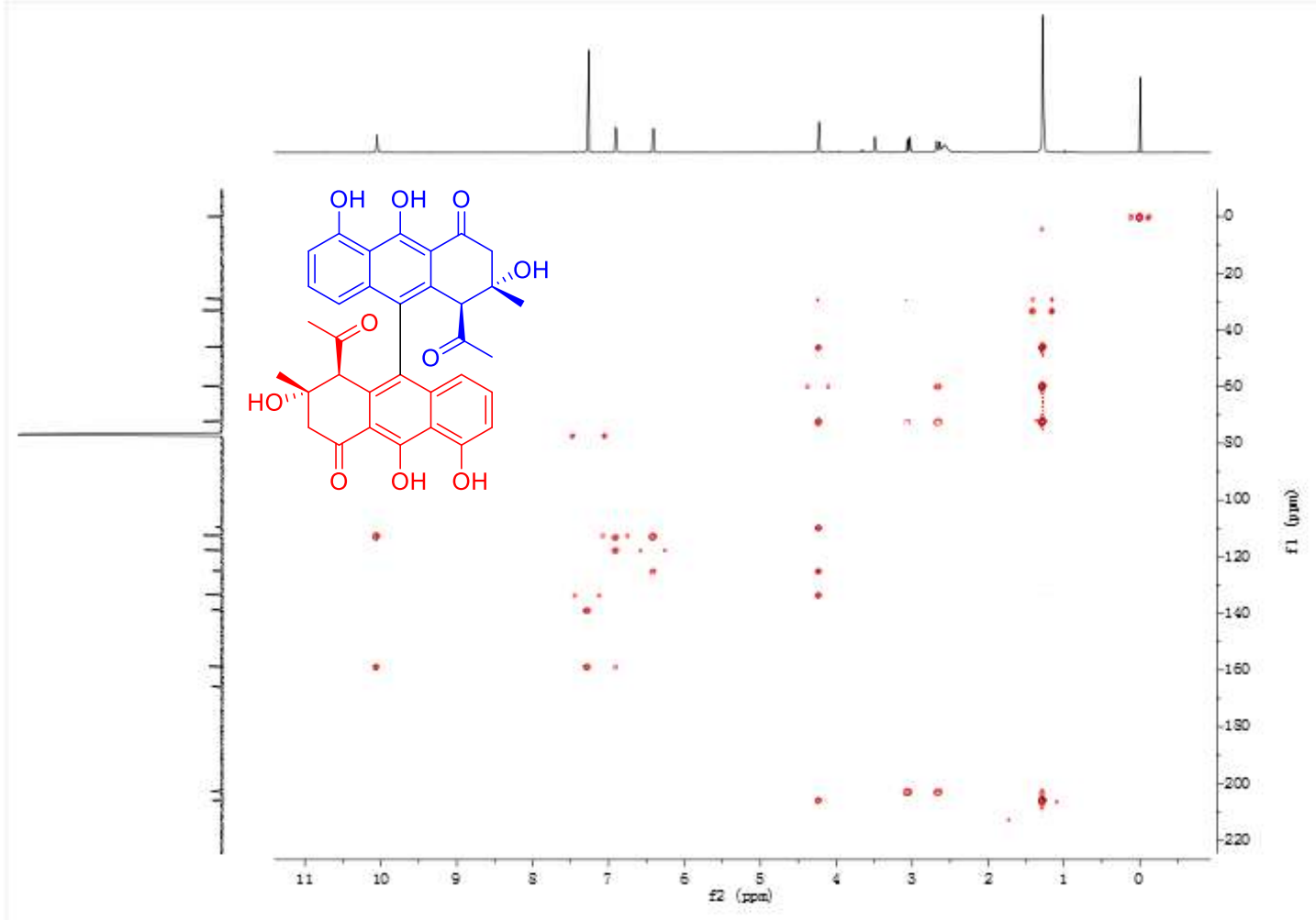

Figure S16. HRESIMS spectrum of 2.

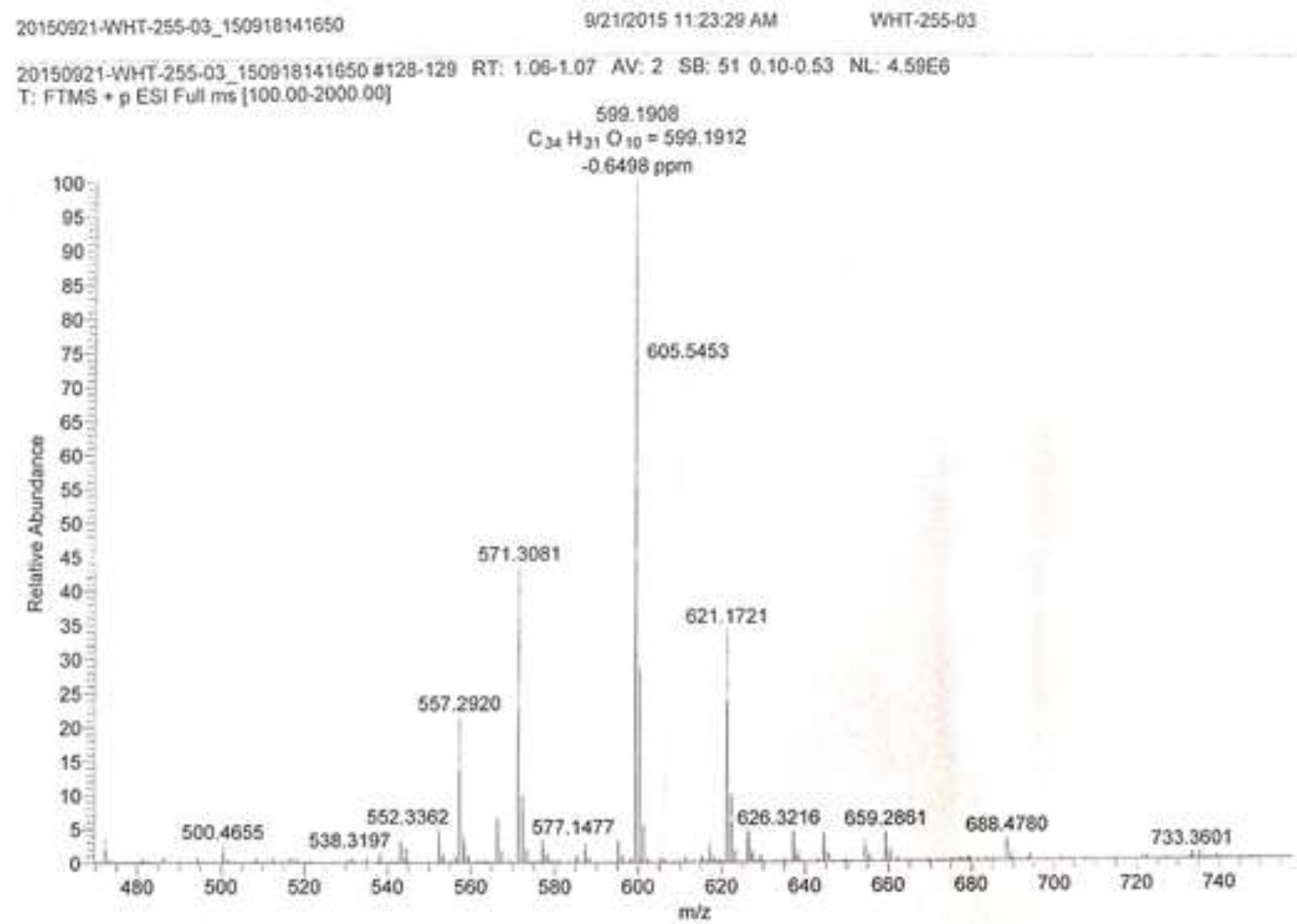


Figure S17. ${ }^{1} \mathrm{H}$ NMR $\left(500 \mathrm{MHz}, \mathrm{CDCl}_{3}\right)$ spectrum of 3.

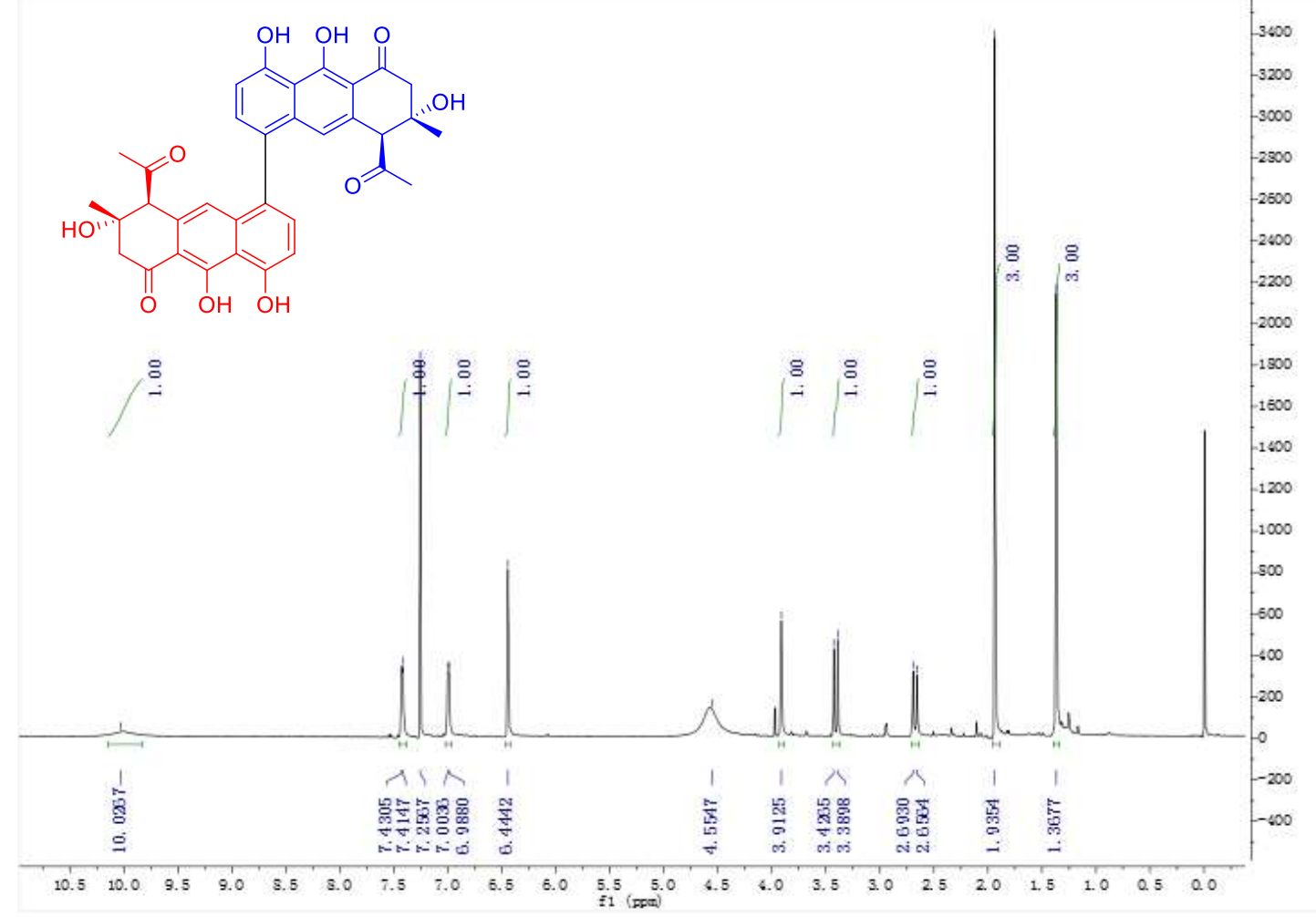

Figure S18. ${ }^{13} \mathrm{C}$ NMR $\left(125 \mathrm{MHz}, \mathrm{CDCl}_{3}\right)$ spectrum of $\mathbf{3}$.
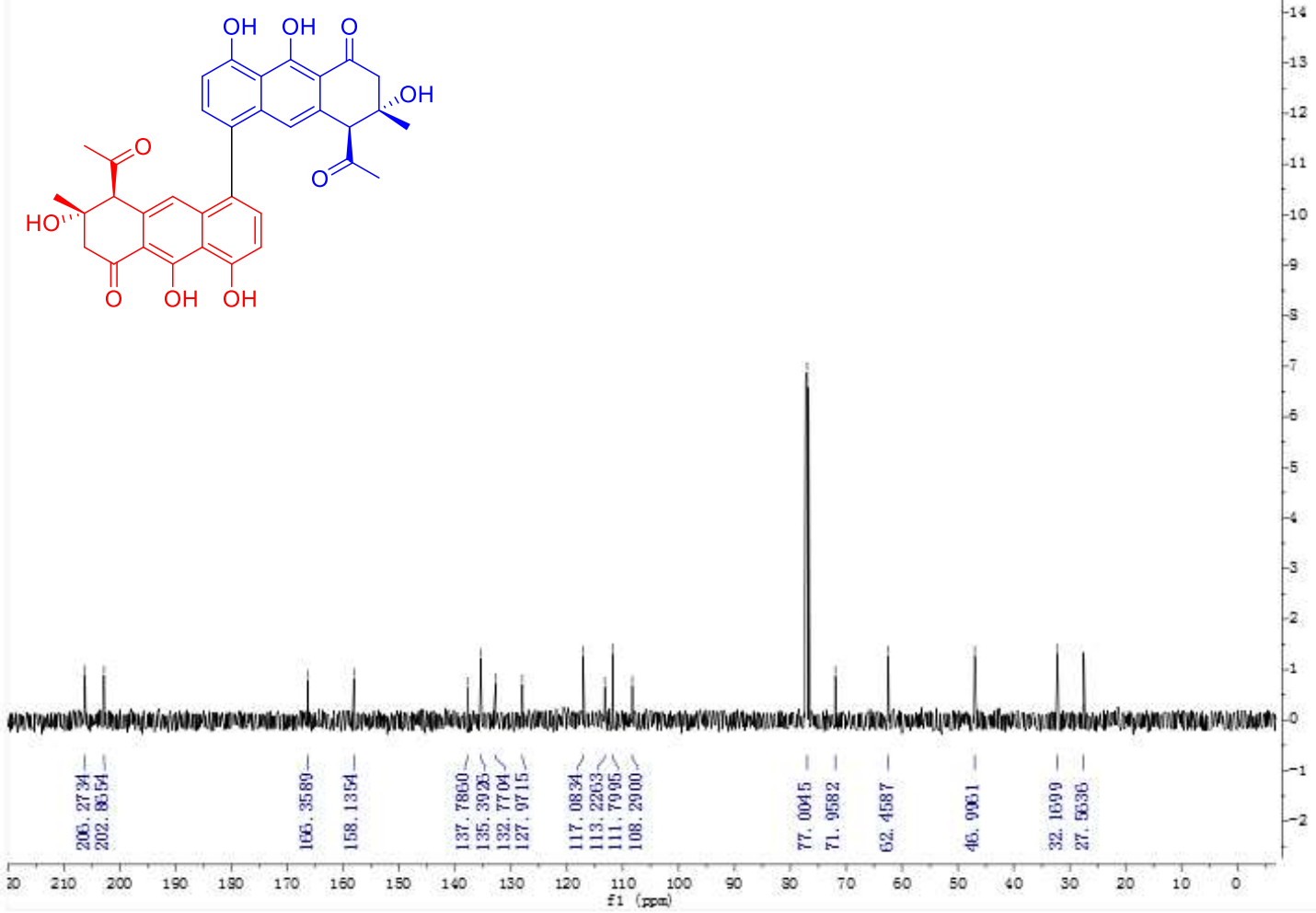
Figure S19. DEPT (125 MHz, $\left.\mathrm{CDCl}_{3}\right)$ spectrum of 3.

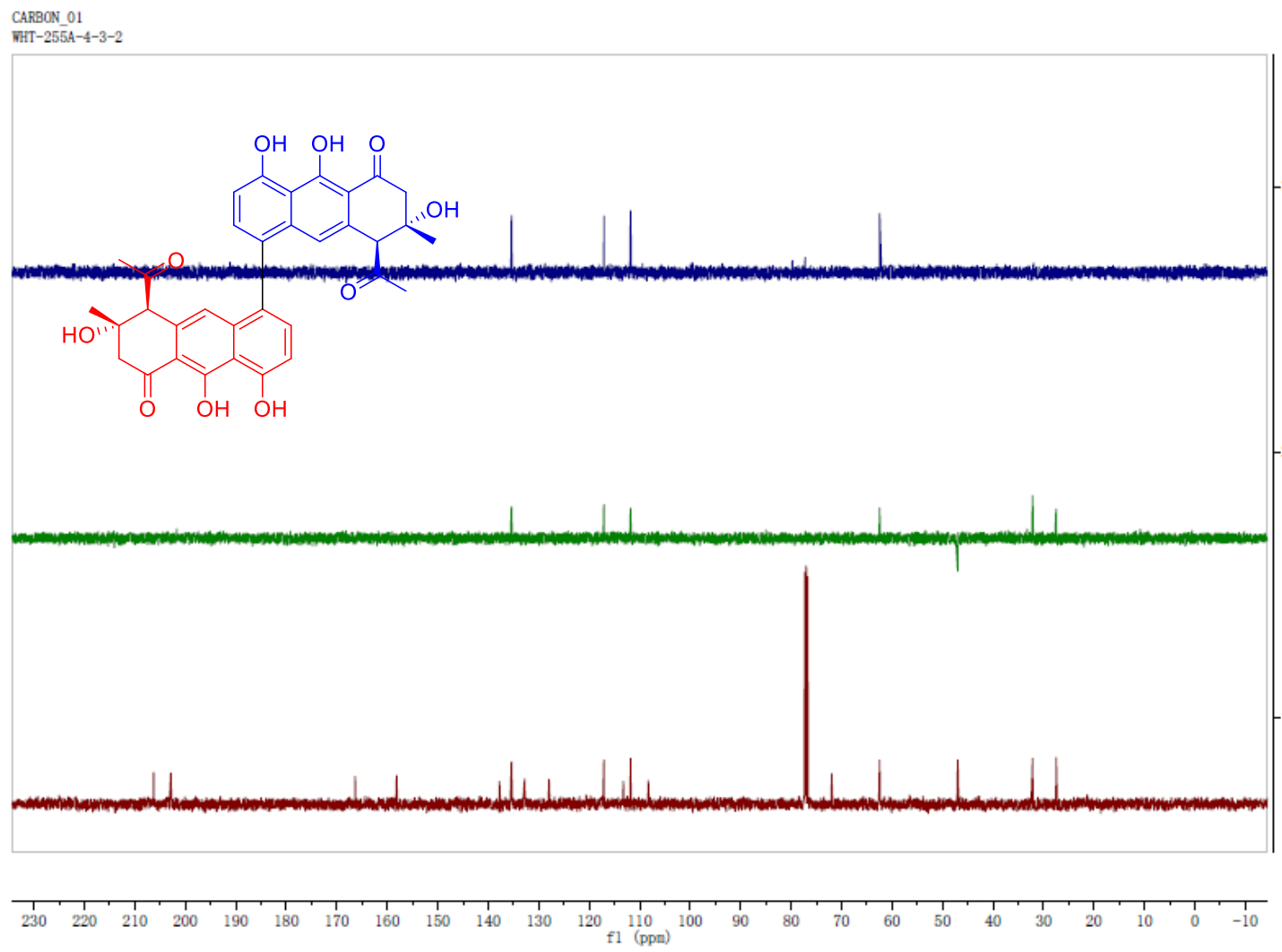

Figure S20. HSQC spectrum of $\mathbf{3}$ in $\mathrm{CDCl}_{3}$.

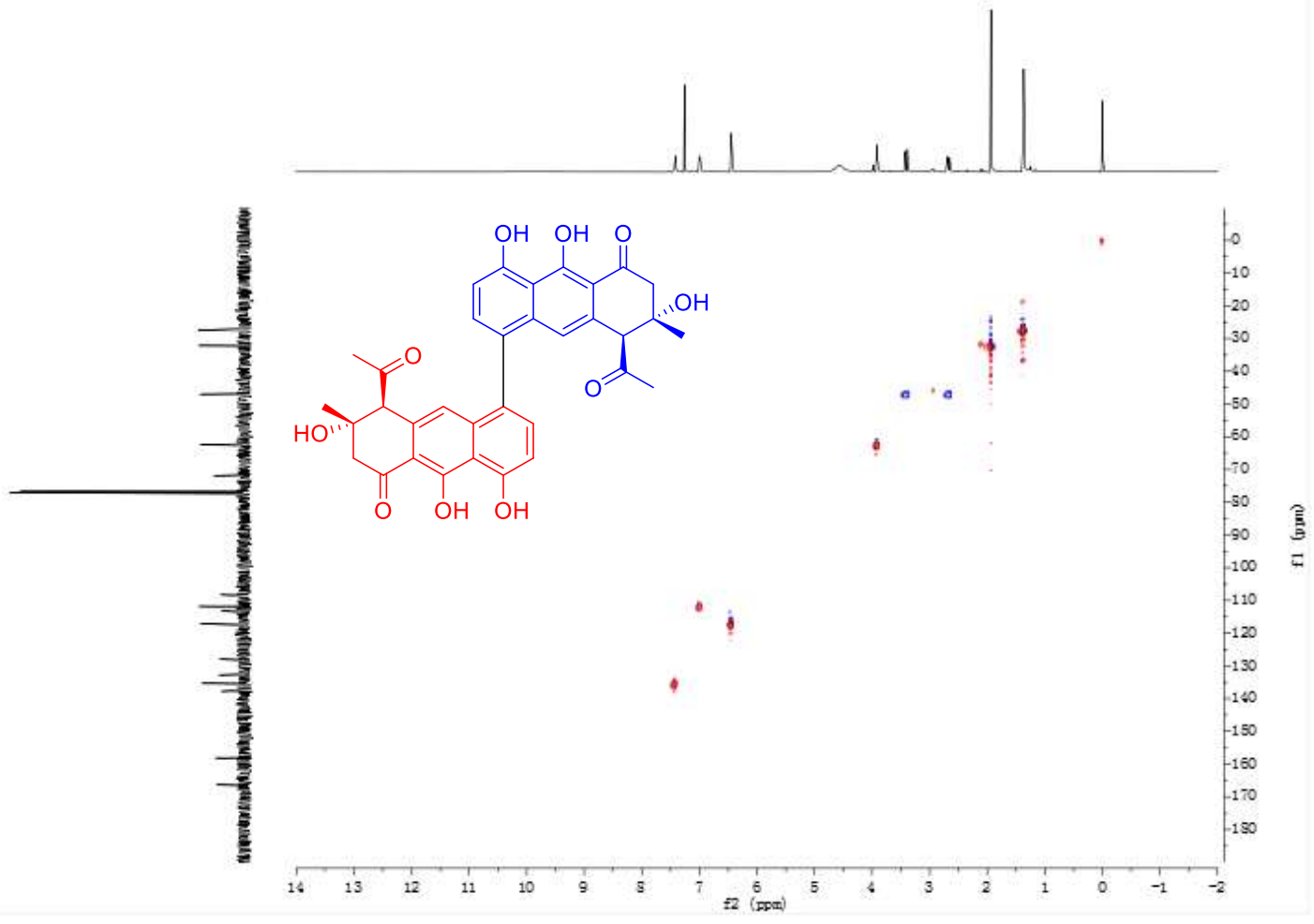


Figure S21. ${ }^{1} \mathrm{H}-{ }^{1} \mathrm{H}$ COSY spectrum of 3 in $\mathrm{CDCl}_{3}$.

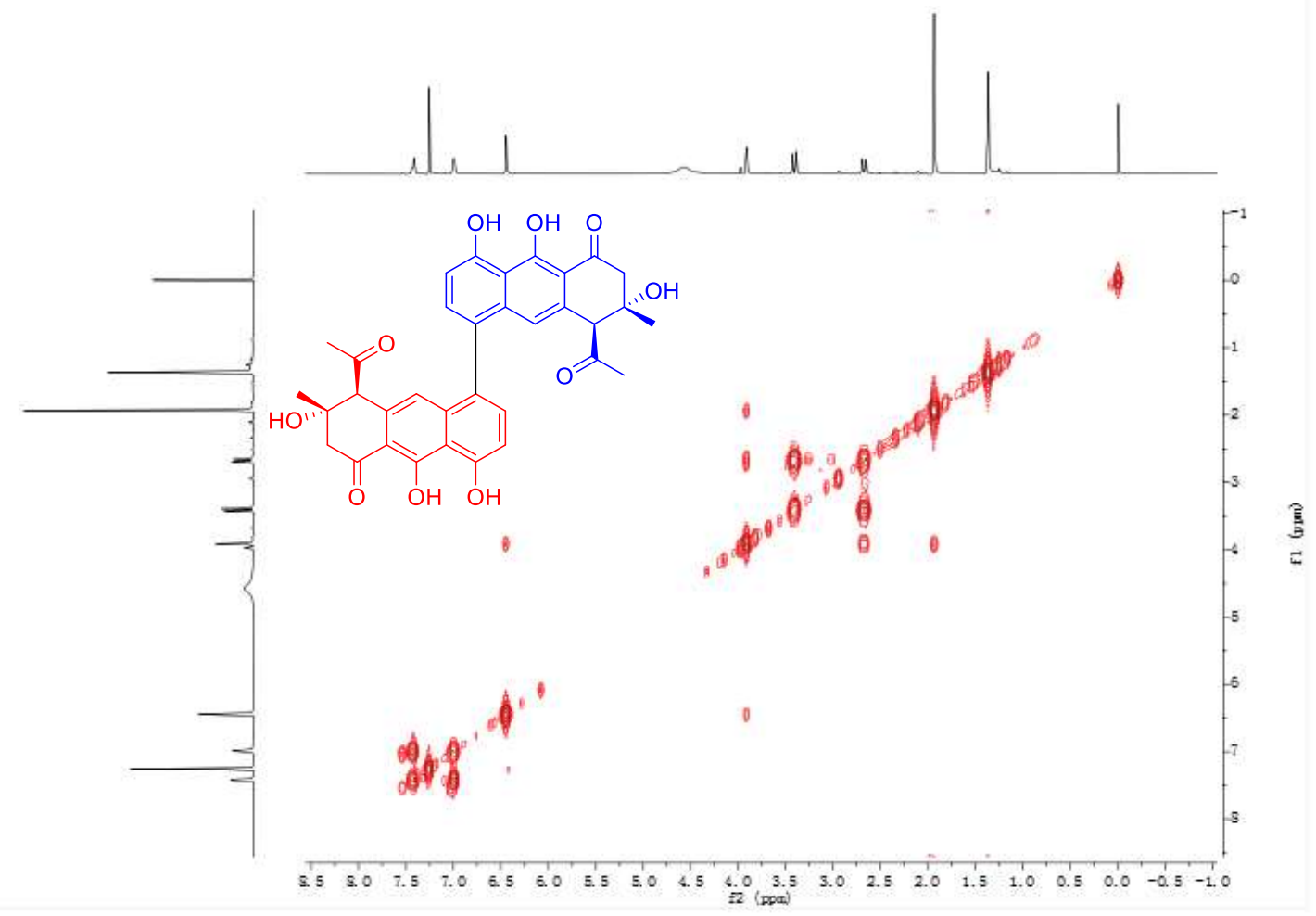

Figure S22. $\mathrm{HMBC}$ spectrum of $\mathbf{3}$ in $\mathrm{CDCl}_{3}$

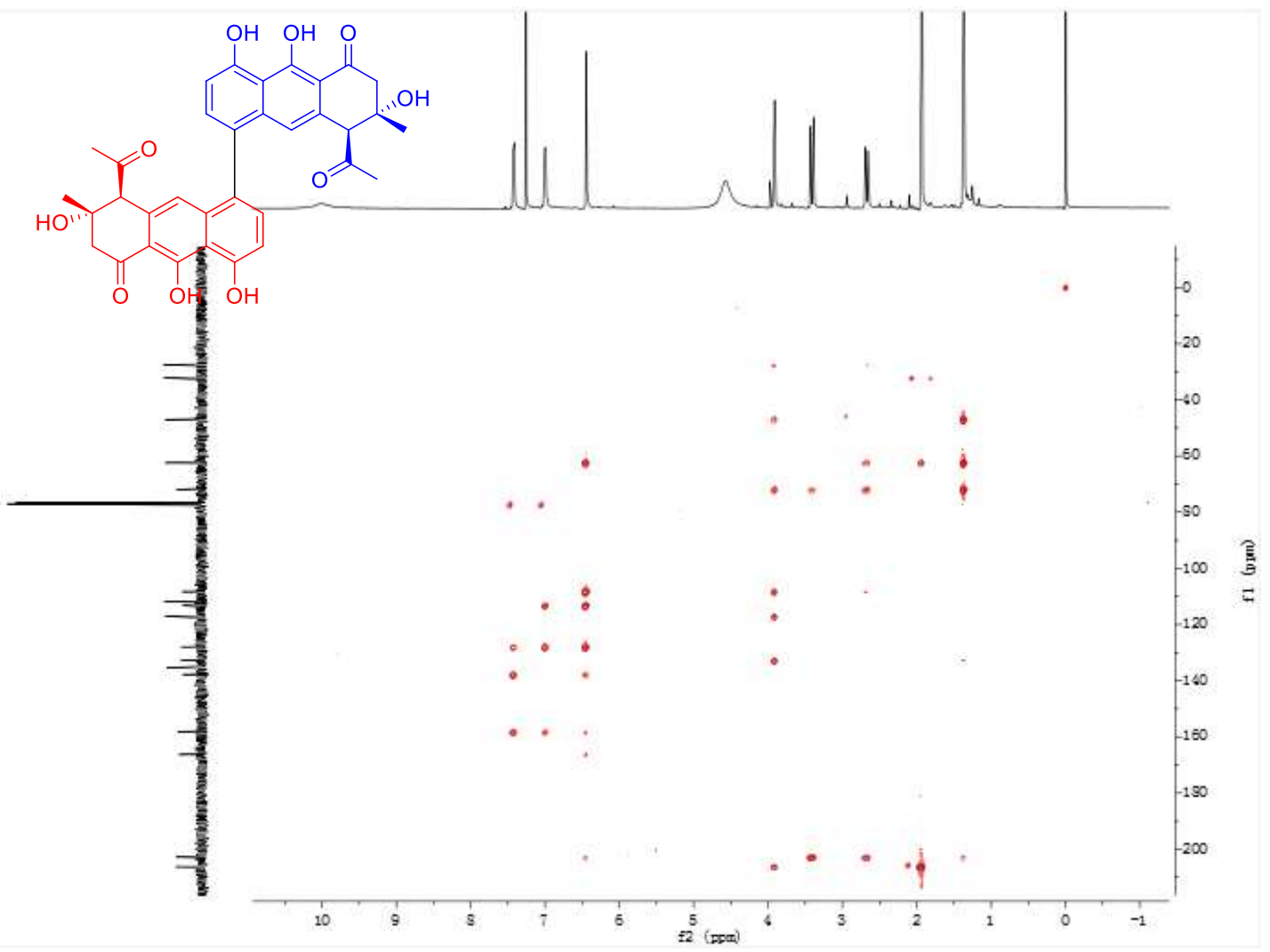


Figure S23. HRESIMS spectrum of 3 .

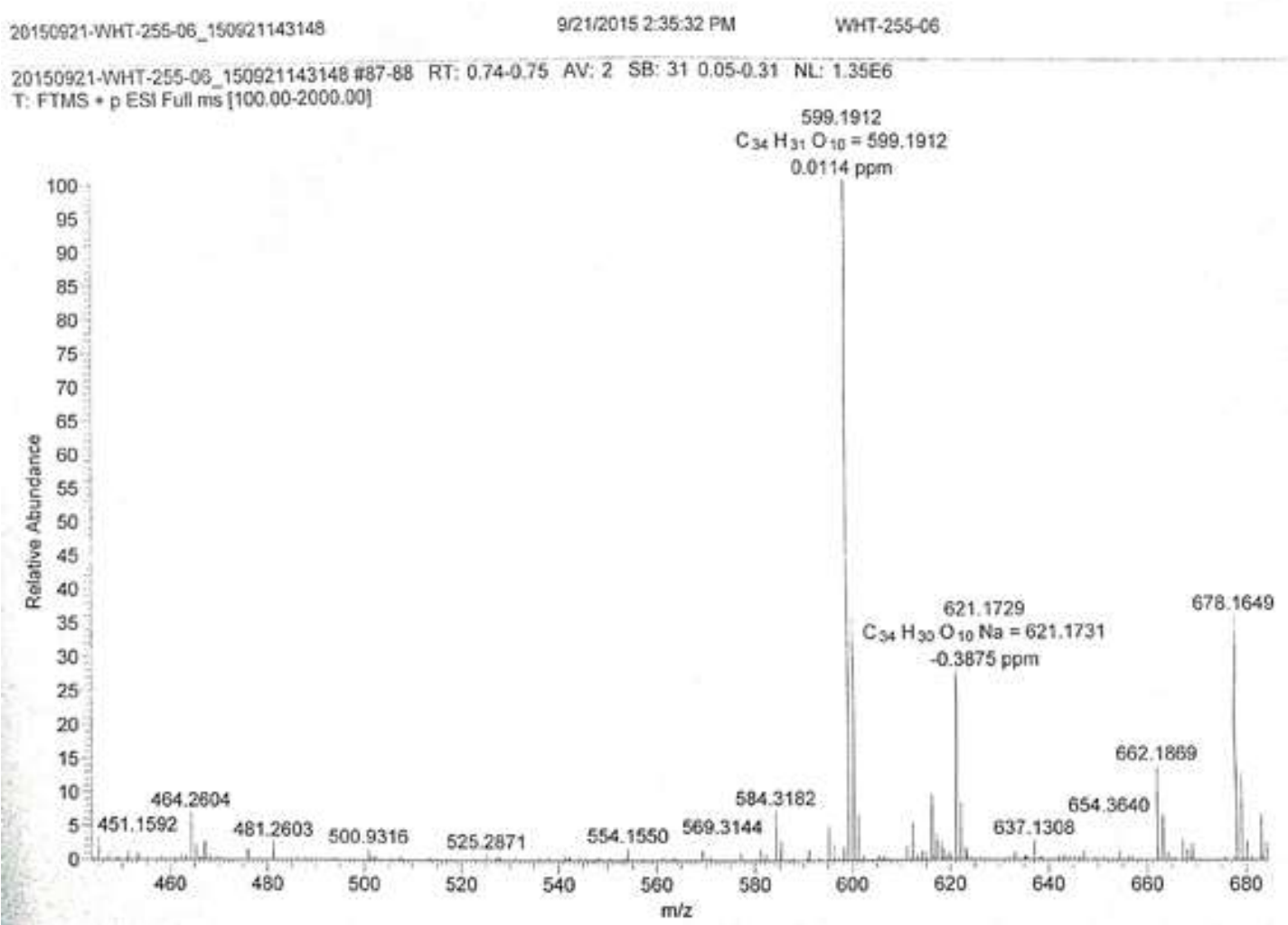

Figure S24. ${ }^{1} \mathrm{H}$ NMR $\left(500 \mathrm{MHz}, \mathrm{CDCl}_{3}\right)$ spectrum of 4.

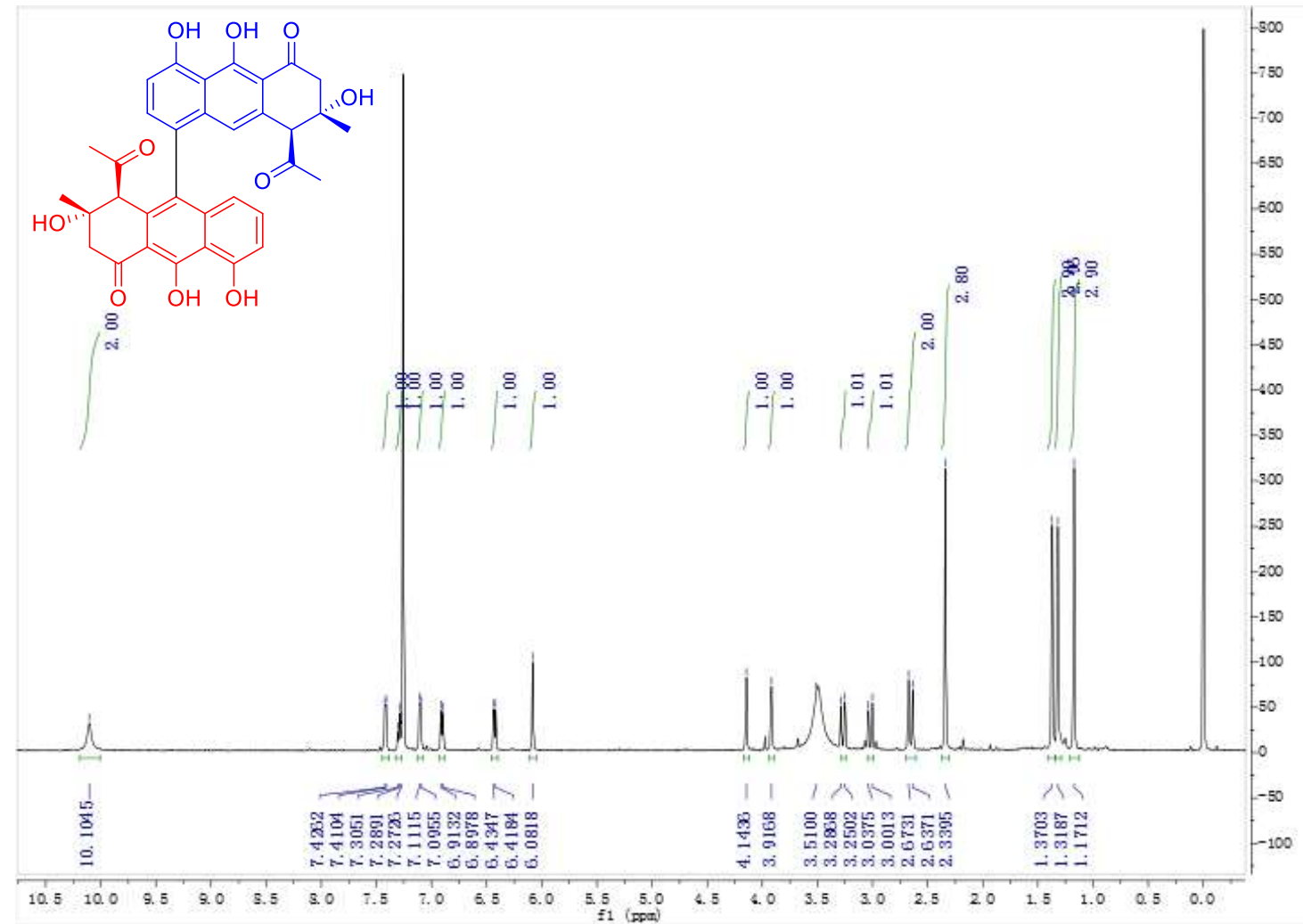


Figure S25. ${ }^{13} \mathrm{C}$ NMR $\left(125 \mathrm{MHz}, \mathrm{CDCl}_{3}\right)$ spectrum of 4 .

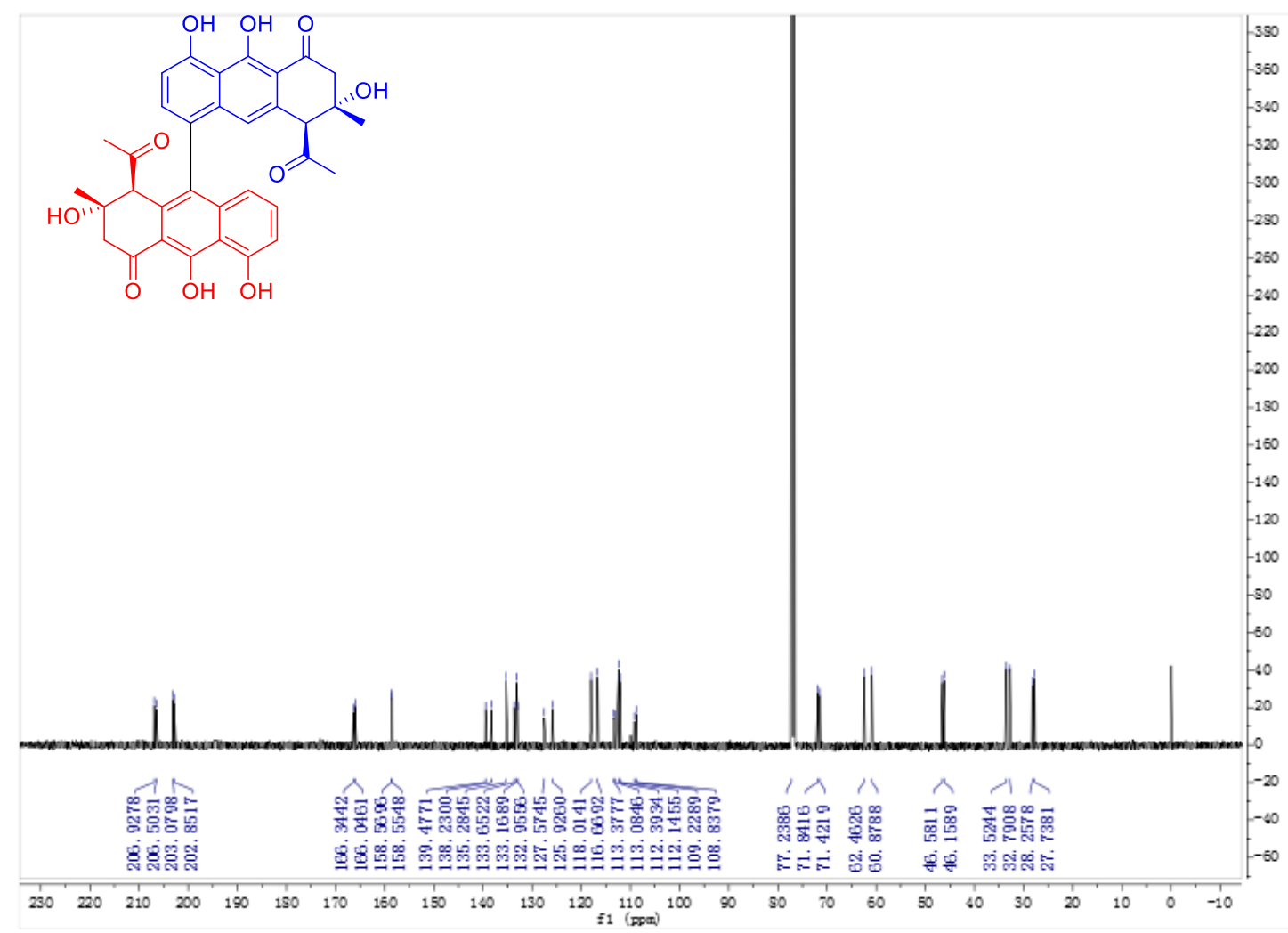

Figure S26. HSQC spectrum of 4 in $\mathrm{CDCl}_{3}$.

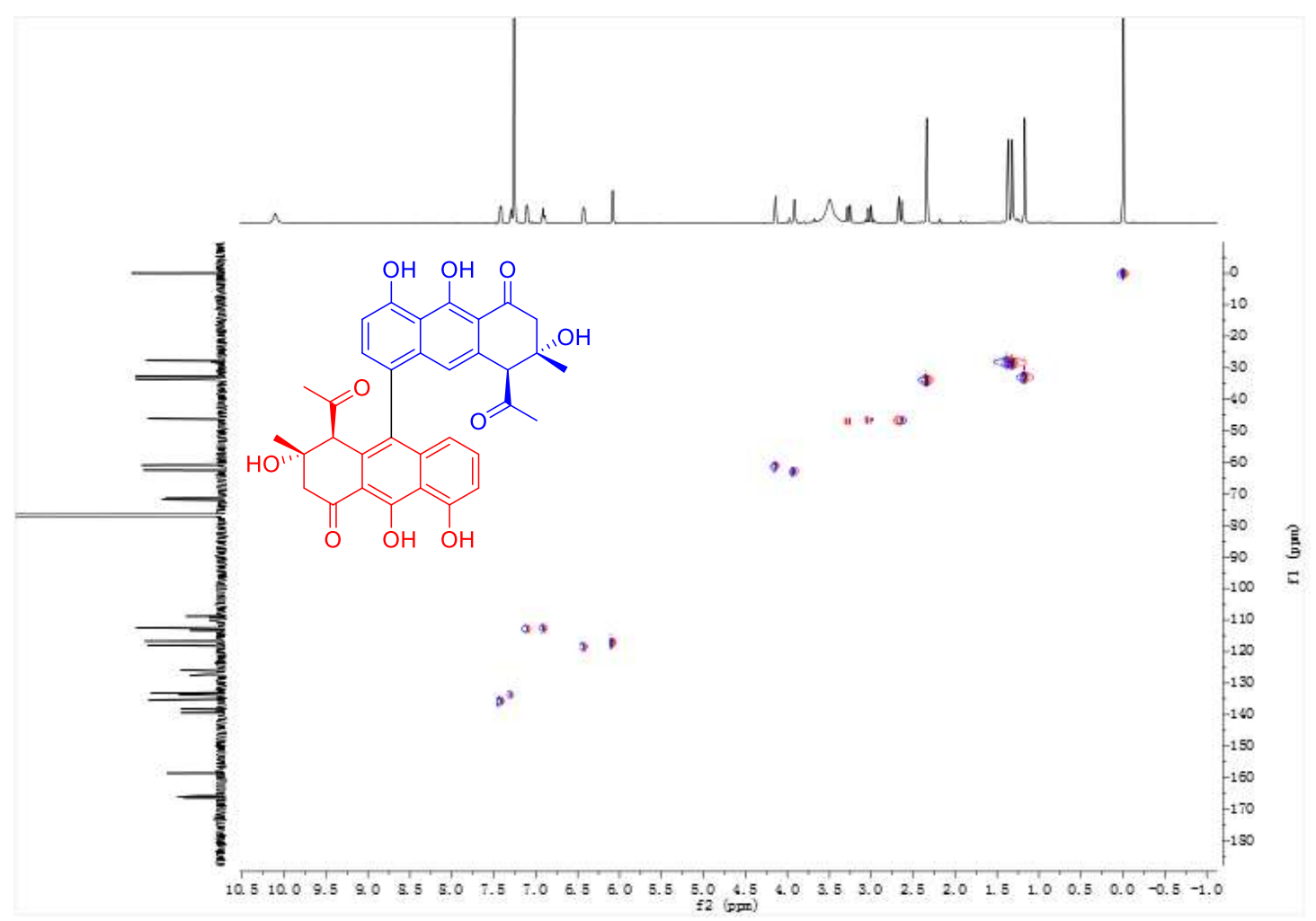


Figure S27. ${ }^{1} \mathrm{H}-{ }^{1} \mathrm{H}$ COSY spectrum of 4 in $\mathrm{CDCl}_{3}$.

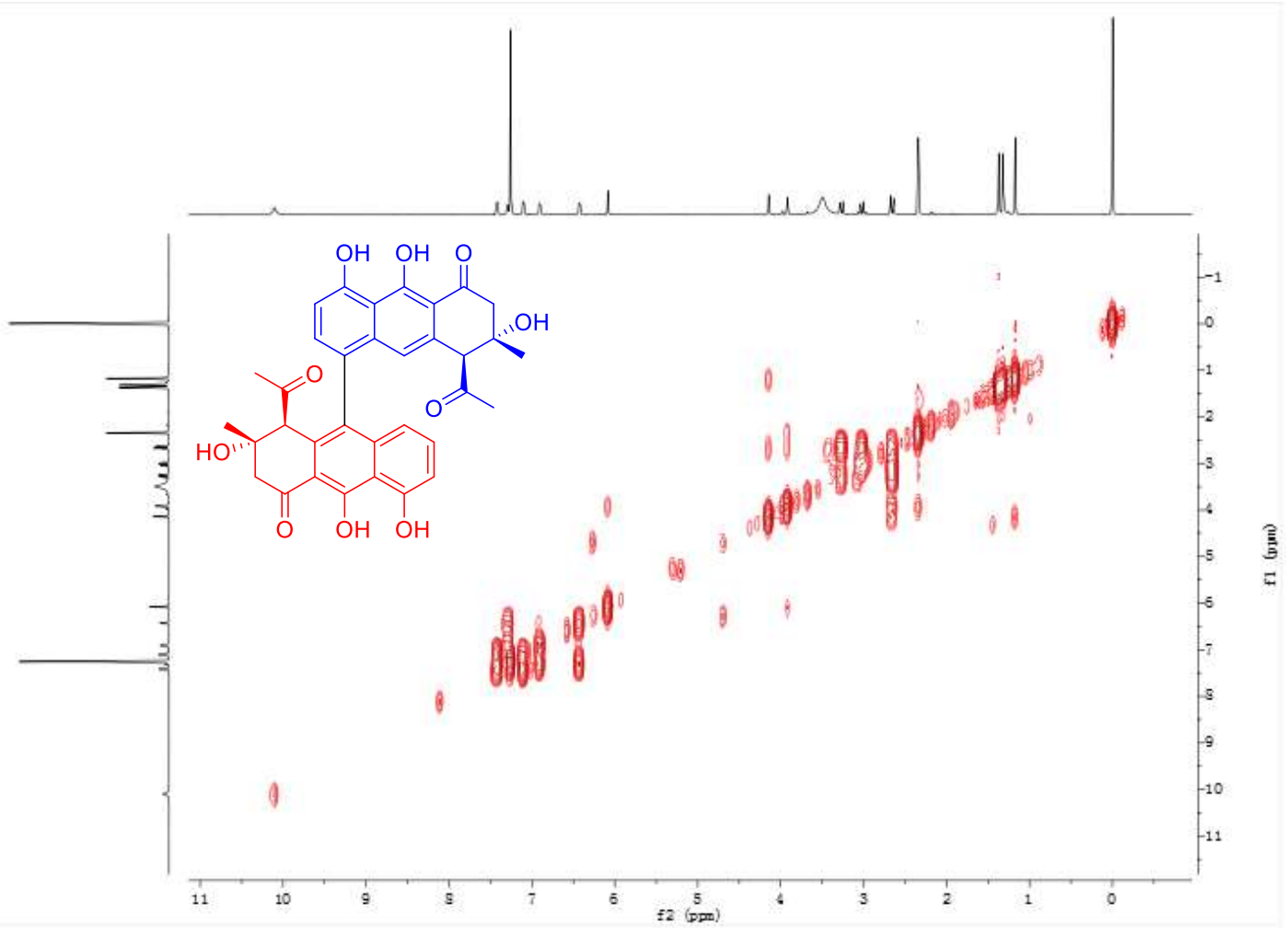

Figure S28. $\mathrm{HMBC}$ spectrum of 4 in $\mathrm{CDCl}_{3}$.

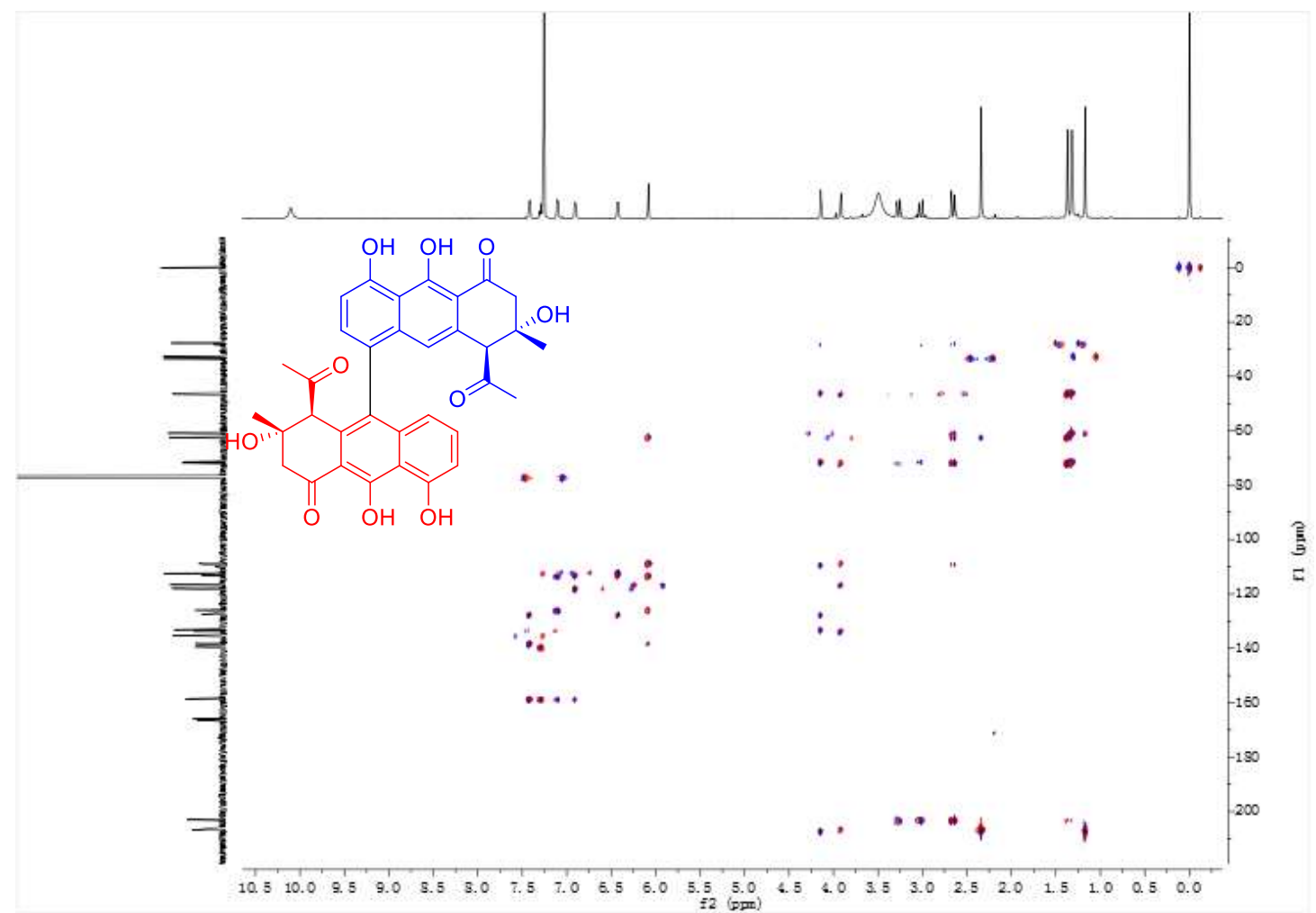


Figure S29. HRESIMS spectrum of 4.

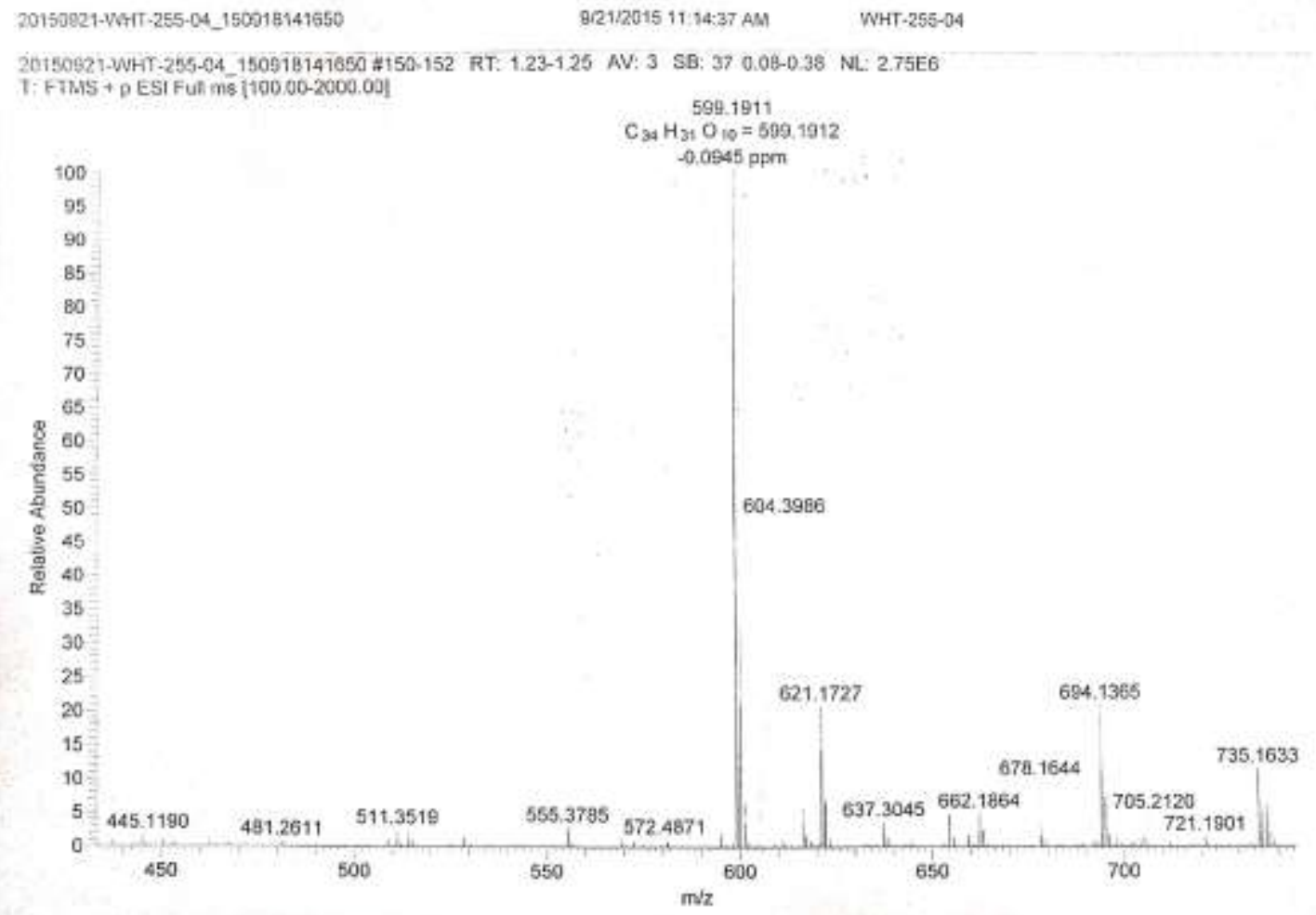

Figure S30. ${ }^{1} \mathrm{H}$ NMR $\left(500 \mathrm{MHz}, \mathrm{CDCl}_{3}\right)$ spectrum of 5.

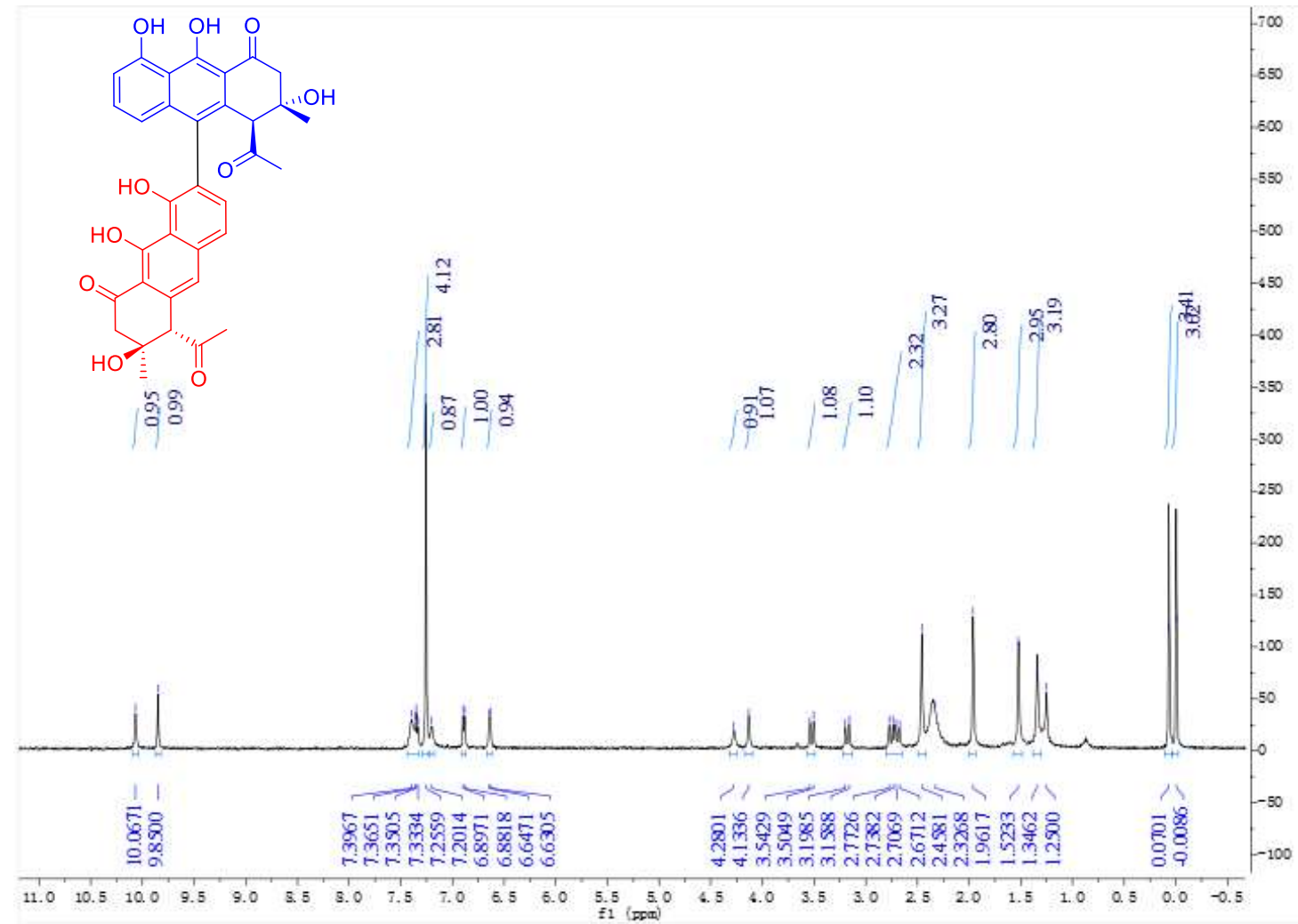


Figure S31. ${ }^{13} \mathrm{C}$ NMR $\left(125 \mathrm{MHz}, \mathrm{CDCl}_{3}\right)$ spectrum of 5 .

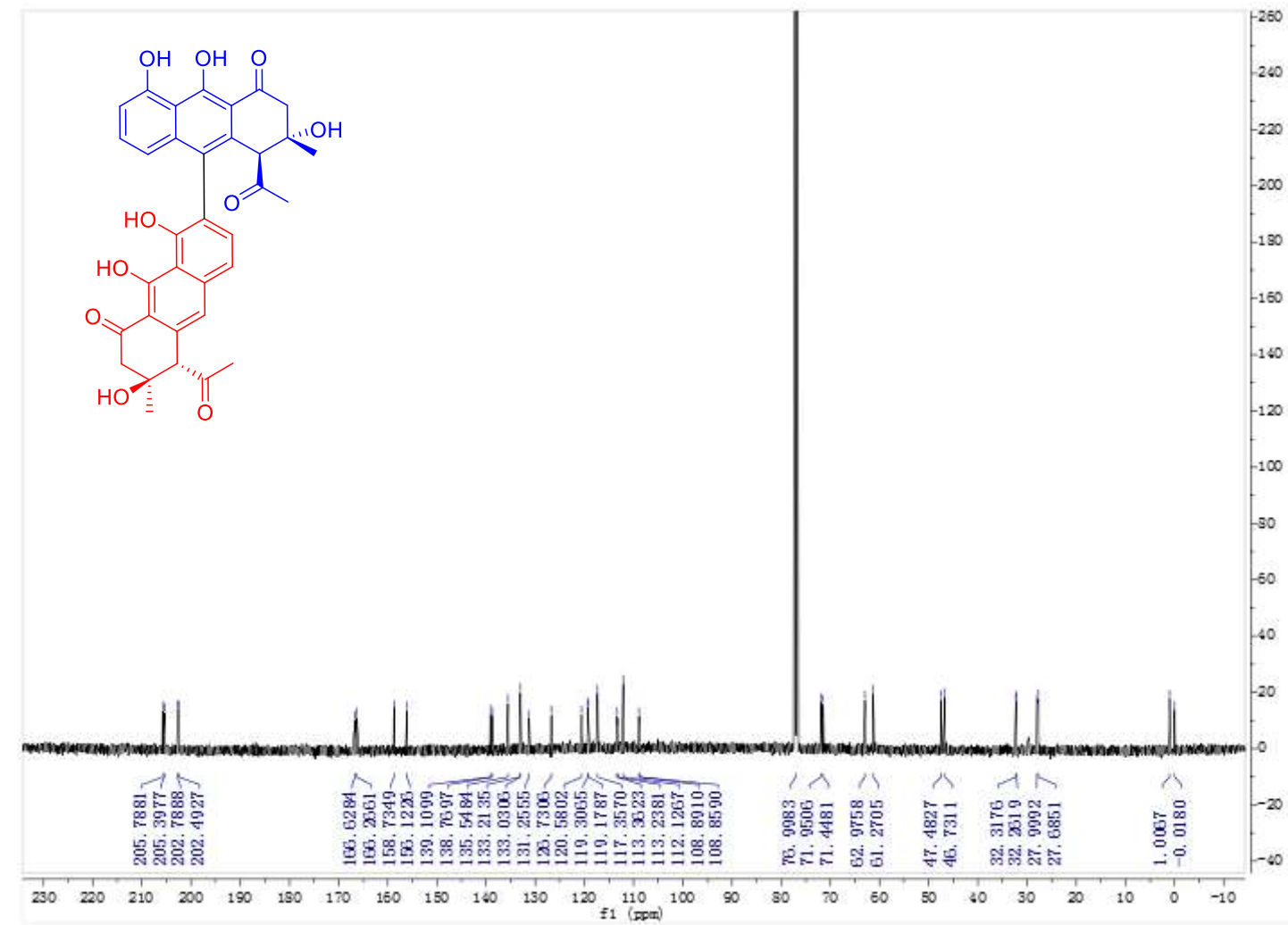

Figure S32. DEPT (125 MHz, $\left.\mathrm{CDCl}_{3}\right)$ spectrum of 5.

CARBON_01
WHT-255A-5-3-5-1

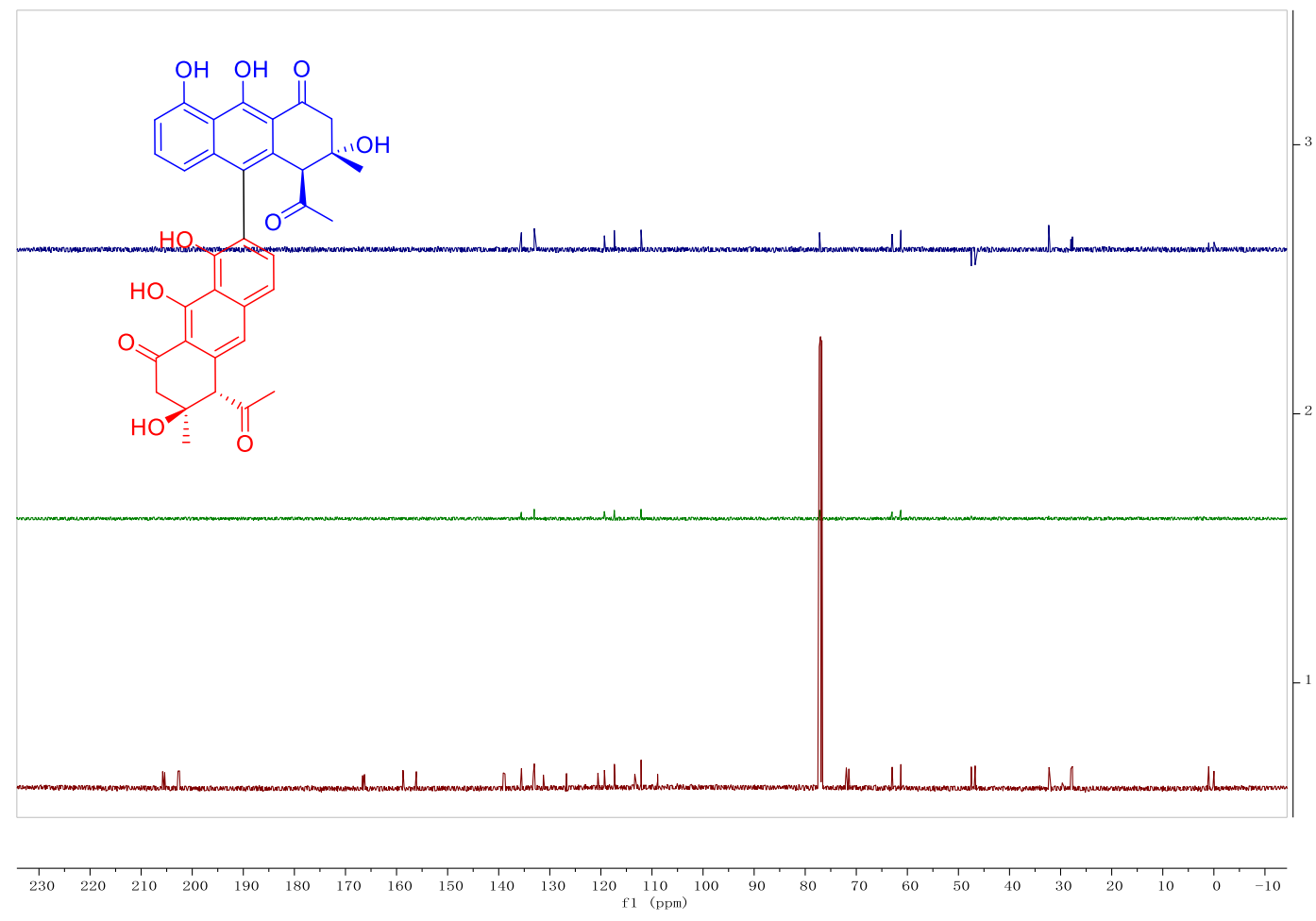


Figure S33. HSQC spectrum of 5 in $\mathrm{CDCl}_{3}$.

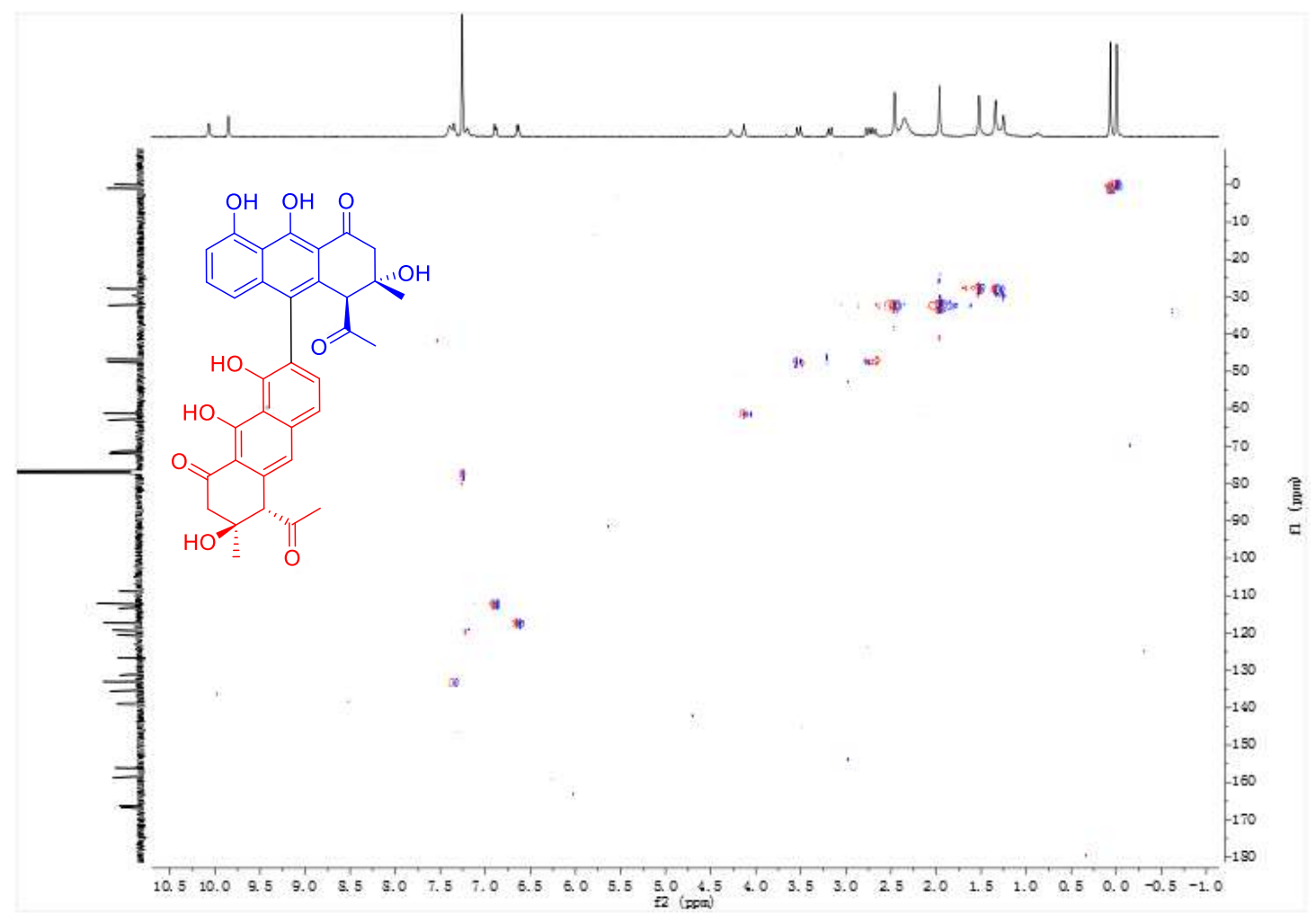

Figure S34. ${ }^{1} \mathrm{H}-{ }^{1} \mathrm{H}$ COSY spectrum of 5 in $\mathrm{CDCl}_{3}$.

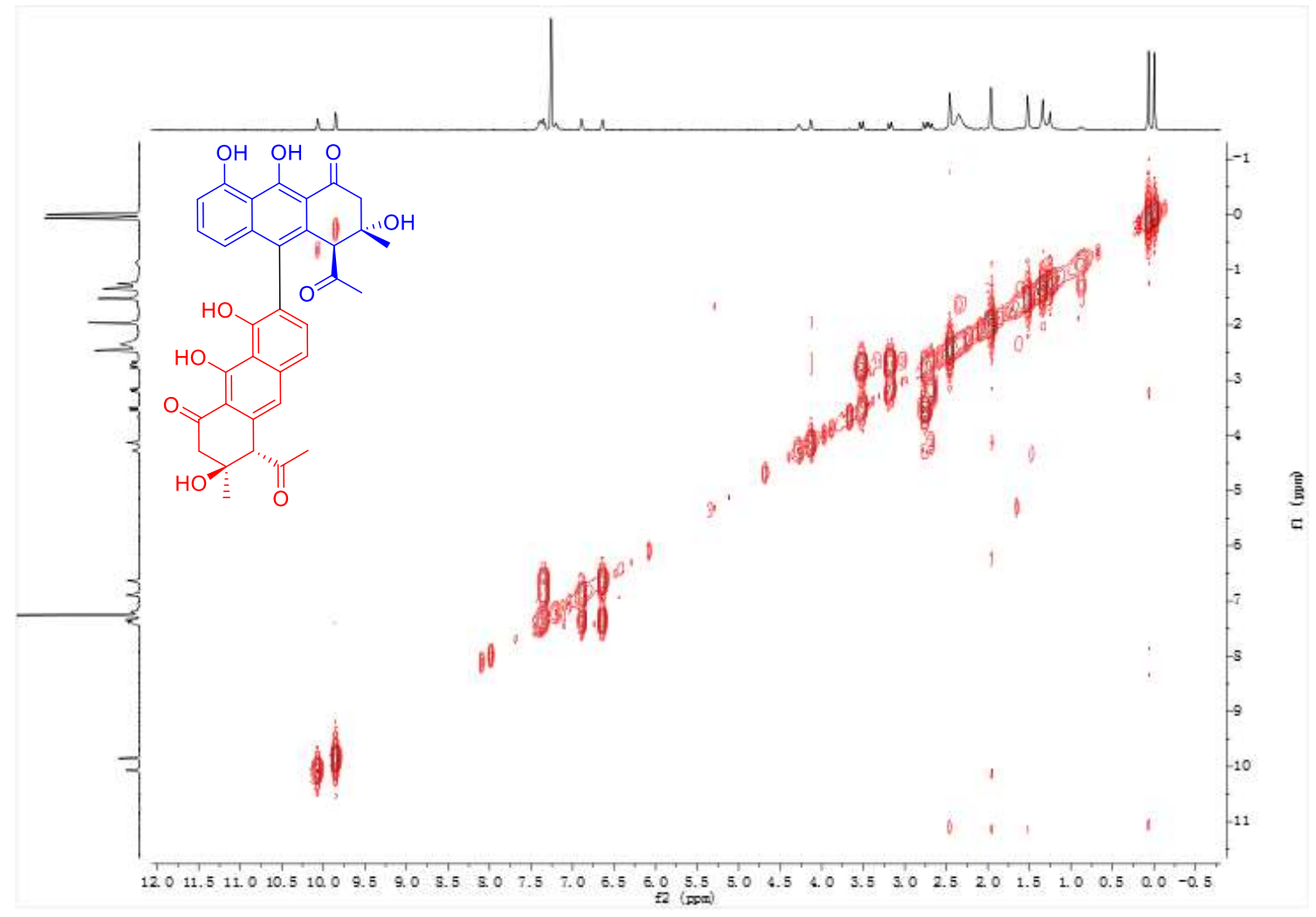


Figure S35. HMBC spectrum of 5 in $\mathrm{CDCl}_{3}$.

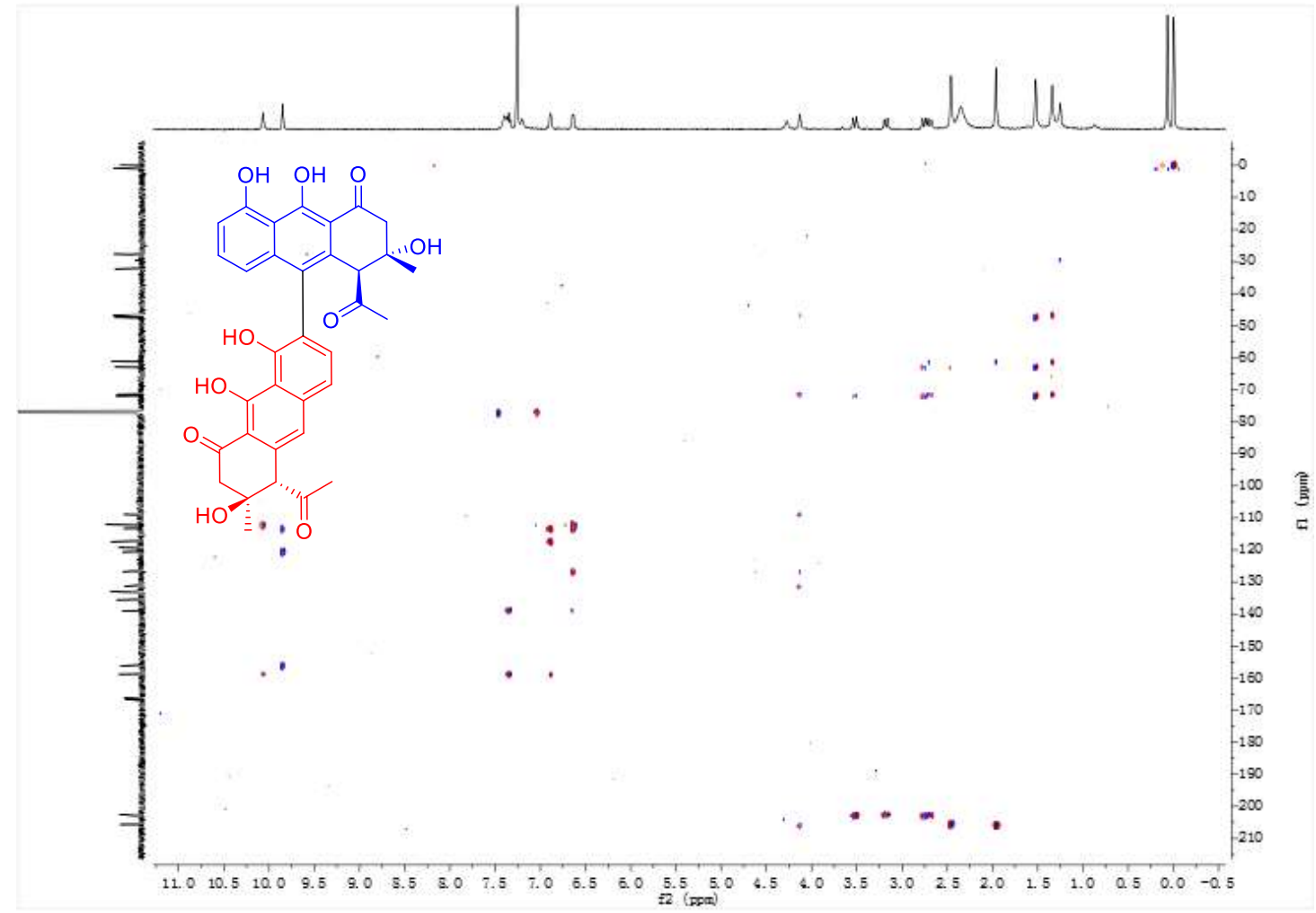

Figure S36. HRESIMS spectrum of 5.

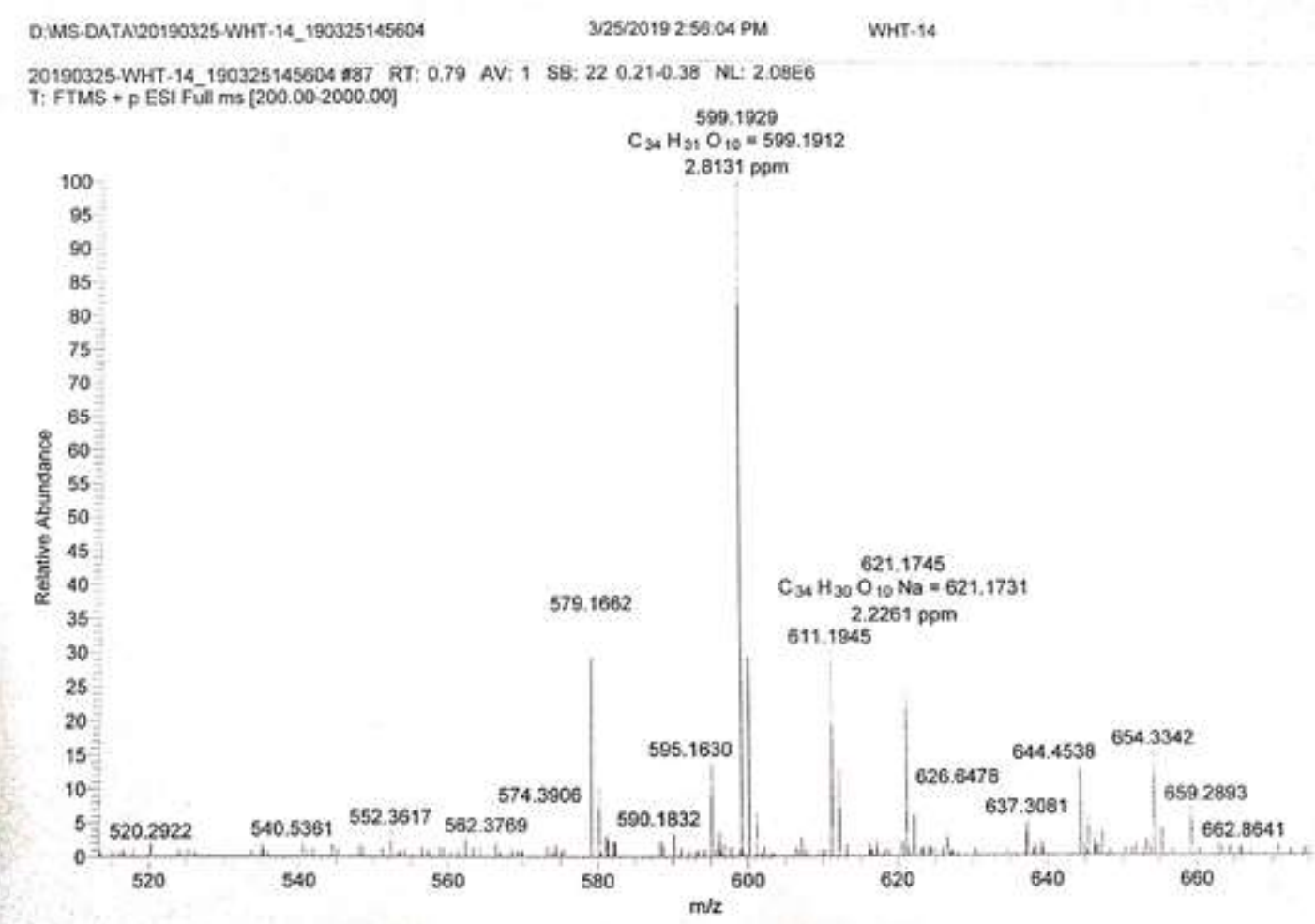


Figure S37. HMBC correlations of compounds 1-5.
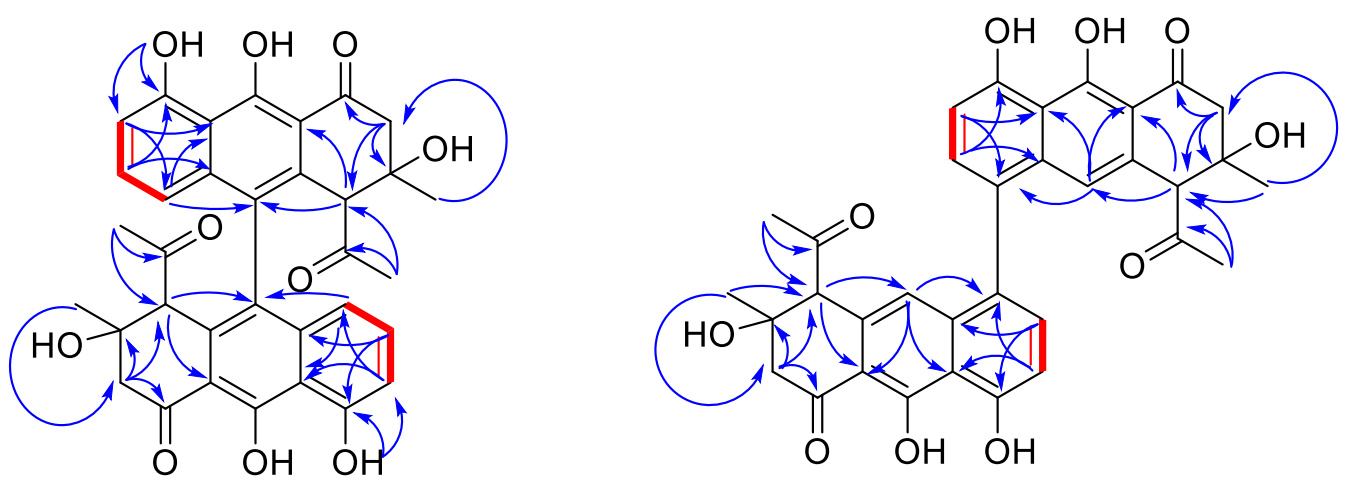

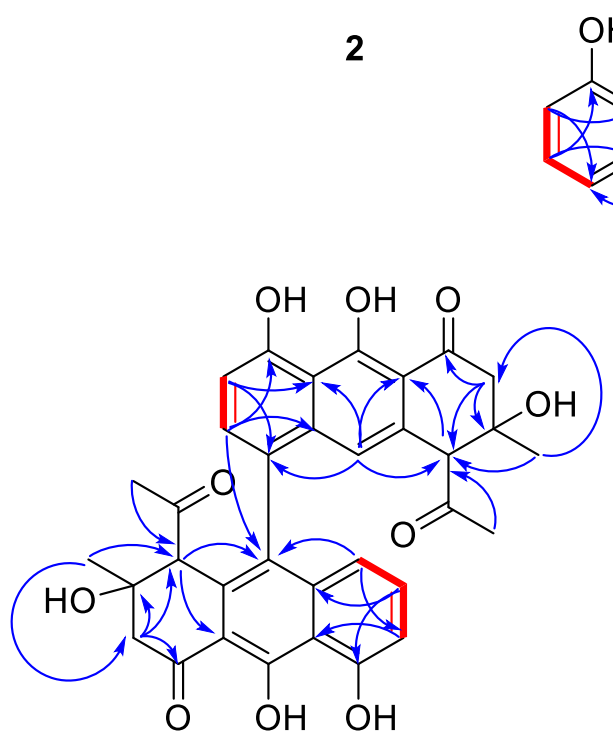

4
3

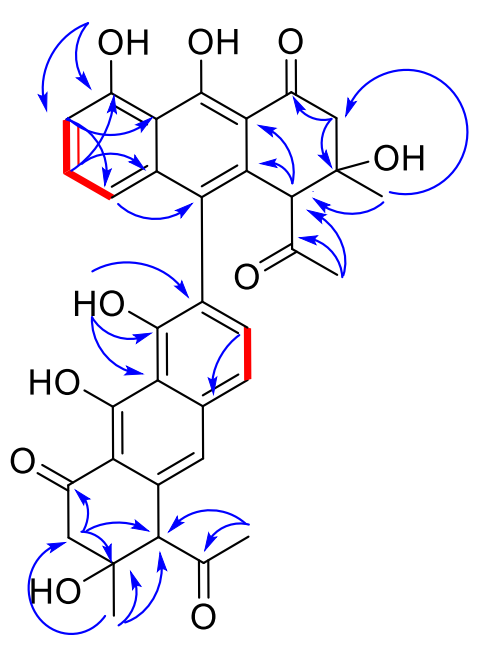

5

$-{ }^{1} \mathrm{H}-{ }^{1} \mathrm{H}$ COSY correlations $\longrightarrow \mathrm{HMBC}$ correlations

Figure S38. Key NOESY and ROESY correlations of compound $\mathbf{1 .}$

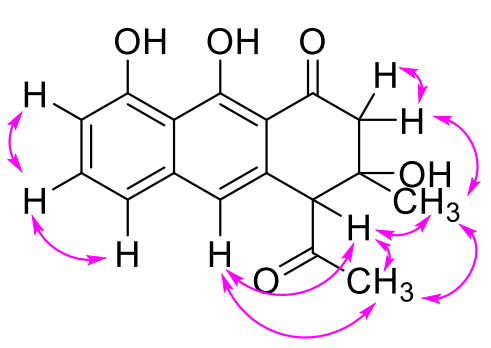

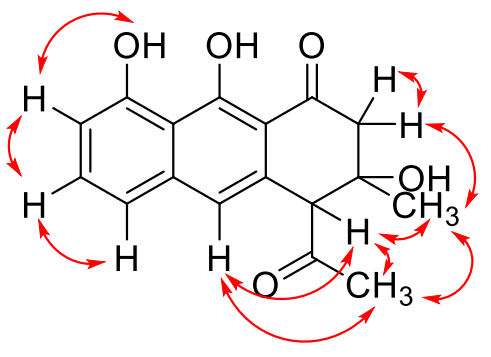

1
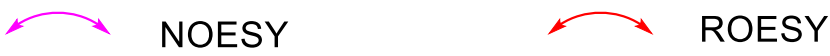
Figure S39. ${ }^{1} \mathrm{H}$ NMR (400 MHz, acetone) spectrum of $\mathbf{1}$.

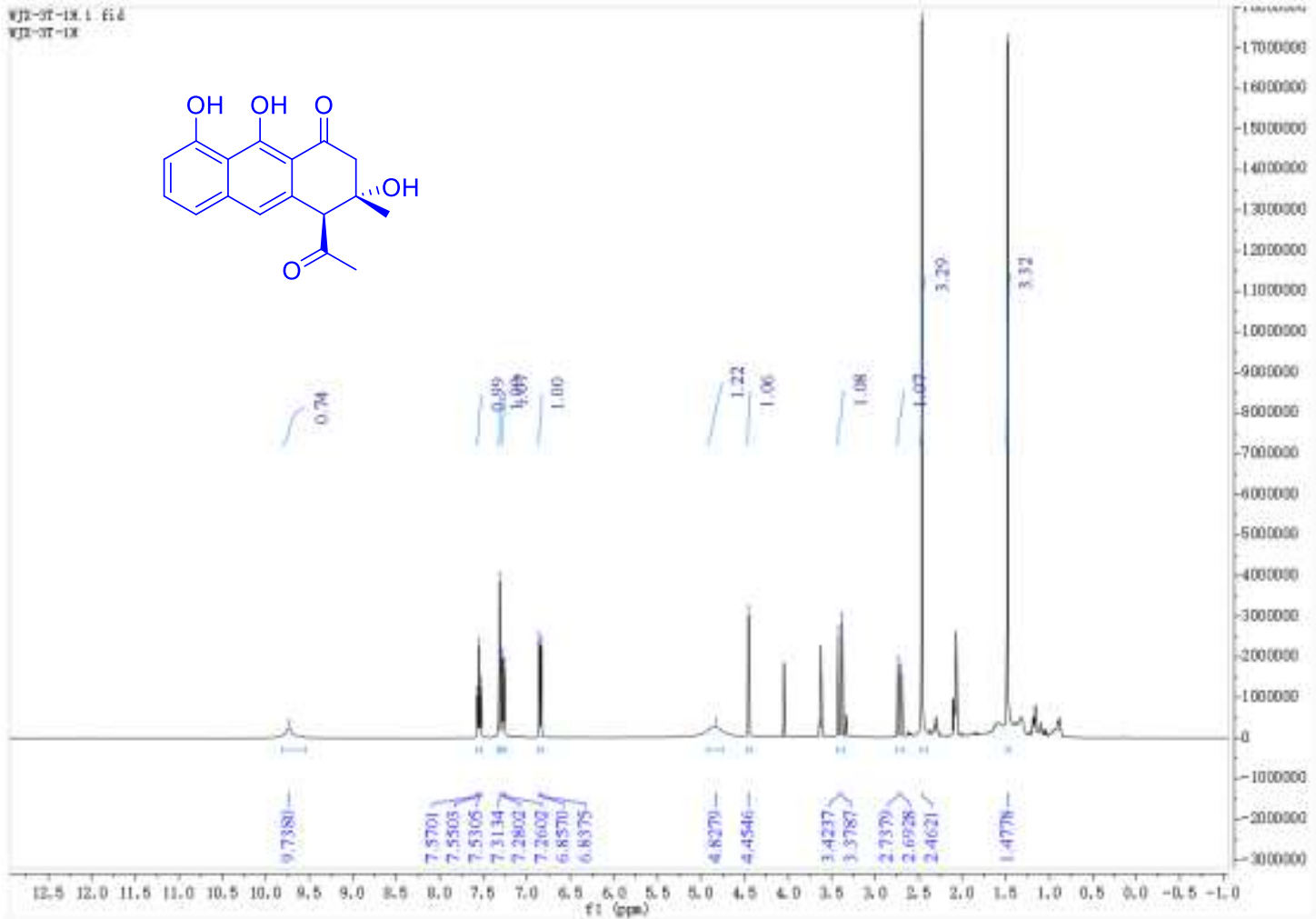

Figure S40. ${ }^{13} \mathrm{C}$ NMR (100 MHz, acetone) spectrum of $\mathbf{1}$.

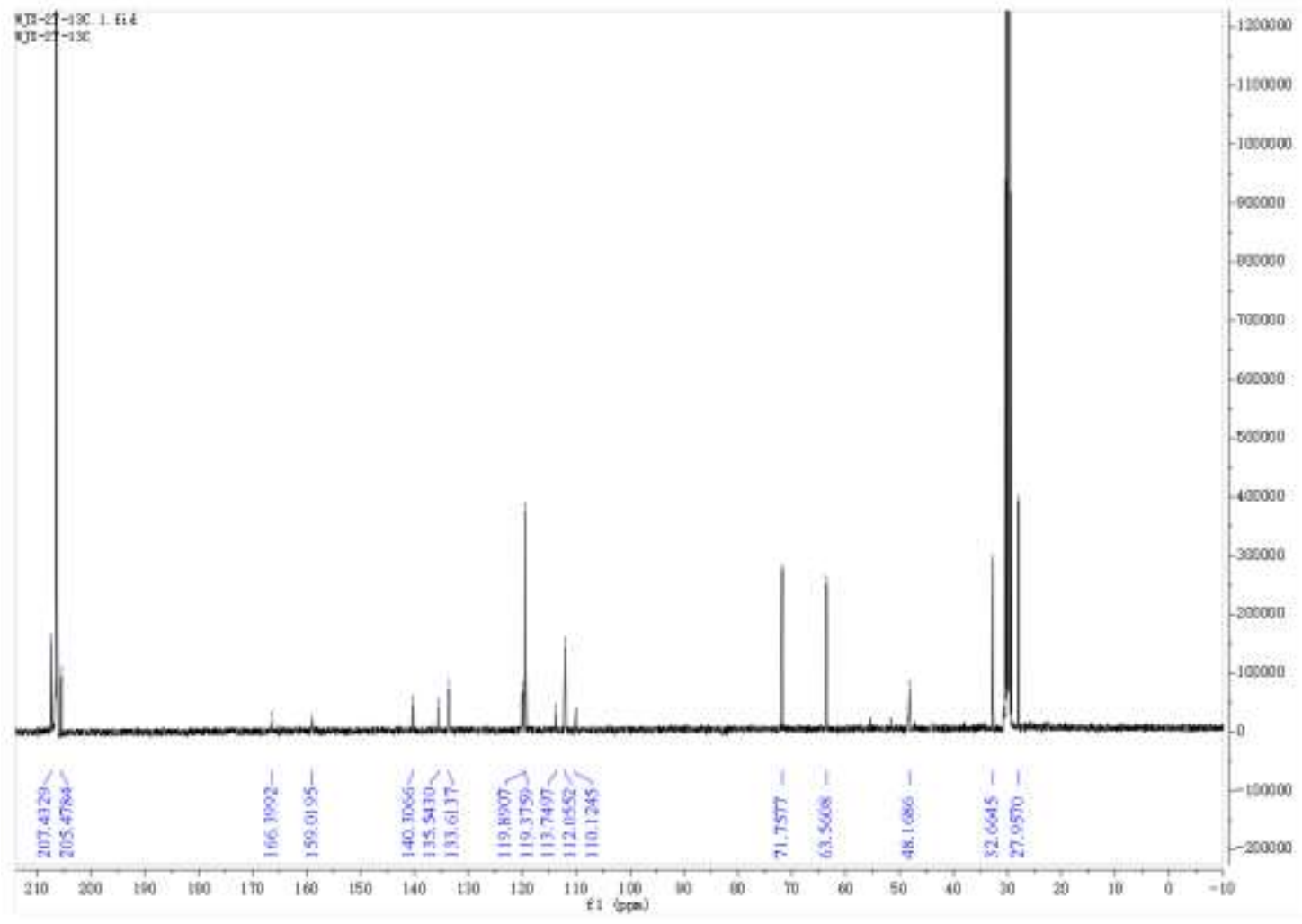


Figure S41. HPLC analysis $(420 \mathrm{~nm})$ between compound $\mathbf{1}$ and julichrome $\mathrm{Q}_{10}$.
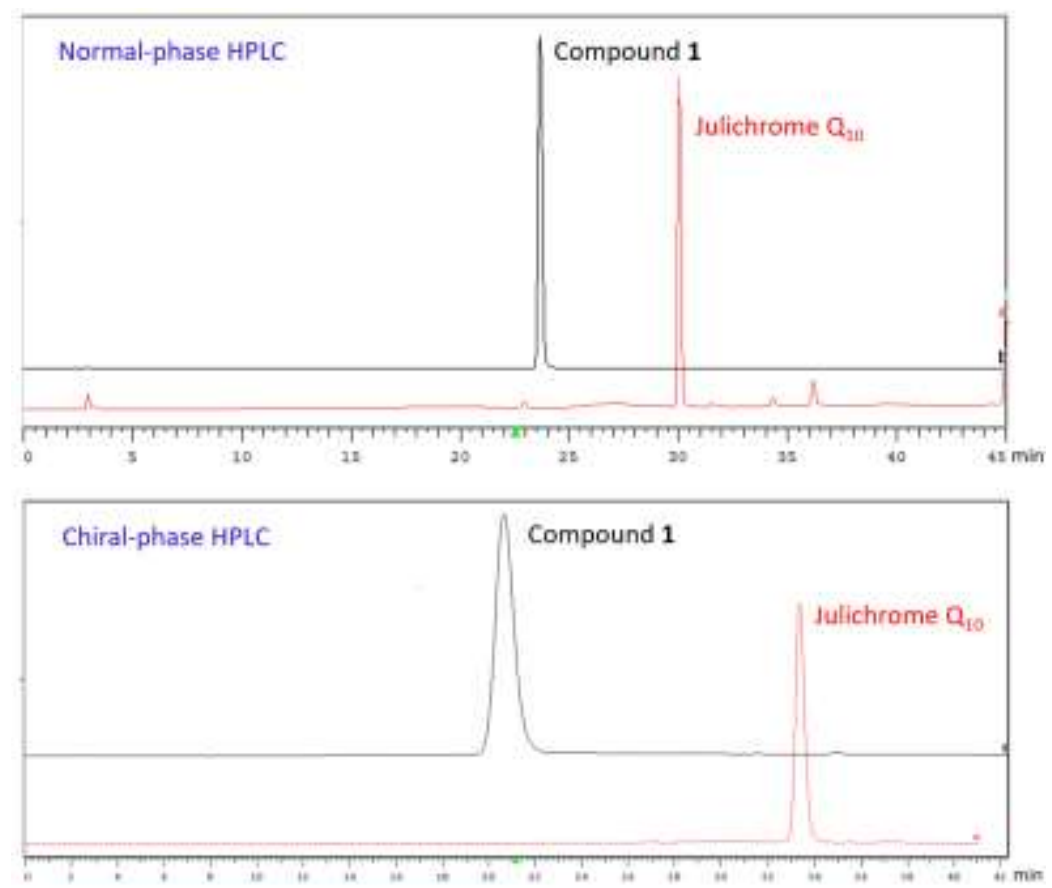

Figure S42. Correlation plots of experimental ${ }^{1} \mathrm{H}$ and ${ }^{13} \mathrm{C}$ NMR chemical shifts versus the corresponding calculated data for $(3 S, 4 R)-\mathbf{1}(\mathbf{1 a})$ and $(3 S, 4 S)-\mathbf{1}(\mathbf{1 b})$.
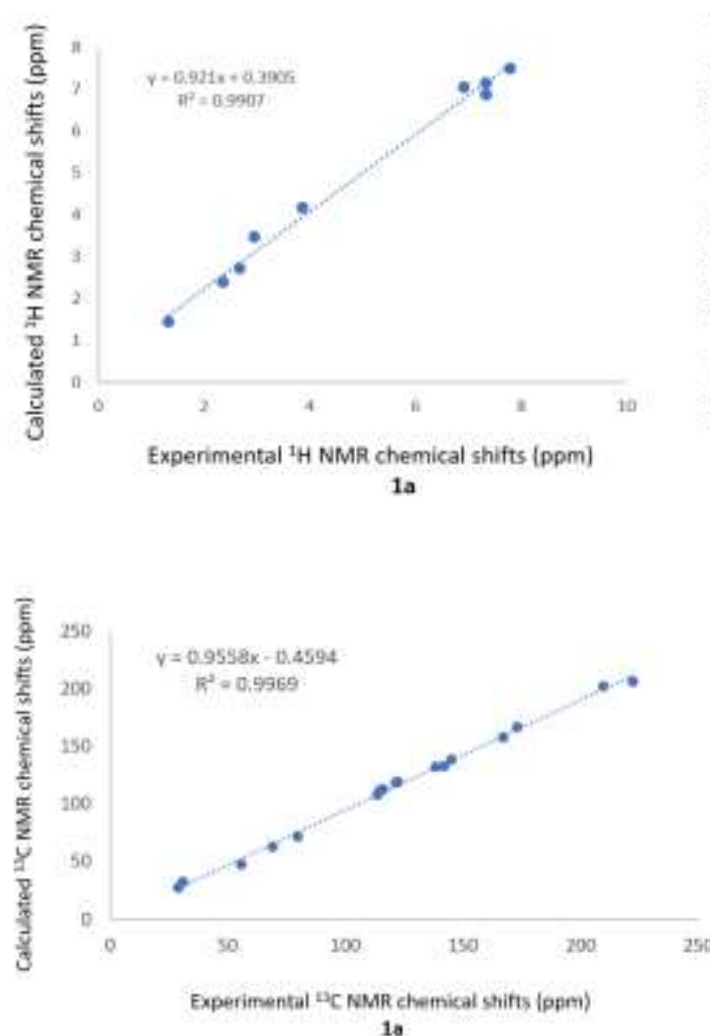

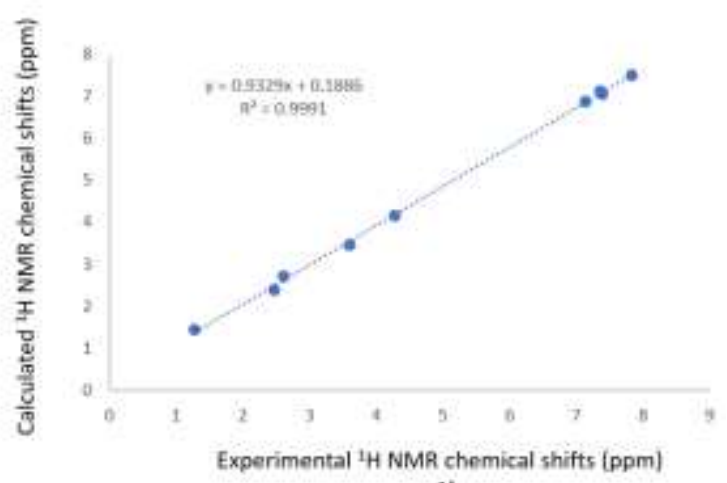

$1 \mathrm{~b}$

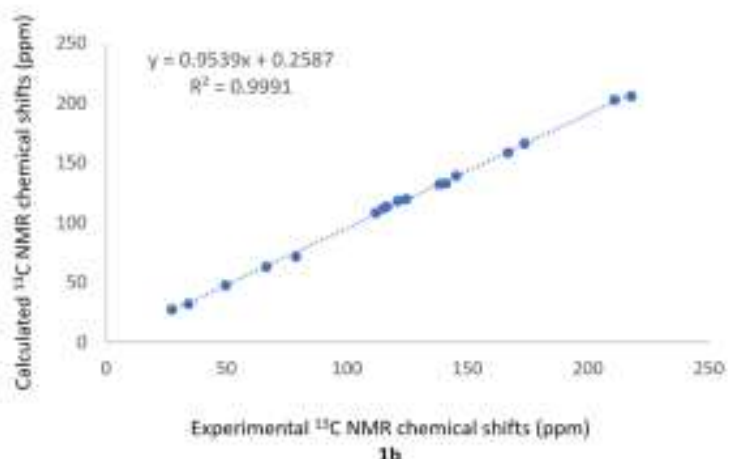

$1 b$ 
Figure S43. Comparison of experimental ECD spectrum of $\mathbf{2}$ with calculated ECD spectra of ( $P$, $\left.3 S, 4 S, 3^{\prime} S, 4^{\prime} S\right)$-2 (2a) versus $\left(M, 3 S, 4 S, 3^{\prime} S, 4^{\prime} S\right)$-2 (2b) and $\left(P, 3 R, 4 R, 3^{\prime} R, 4^{\prime} R\right)$-2 (2c) versus $\left(M, 3 R, 4 R, 3^{\prime} R, 4^{\prime} R\right)-2(\mathbf{2 d})$
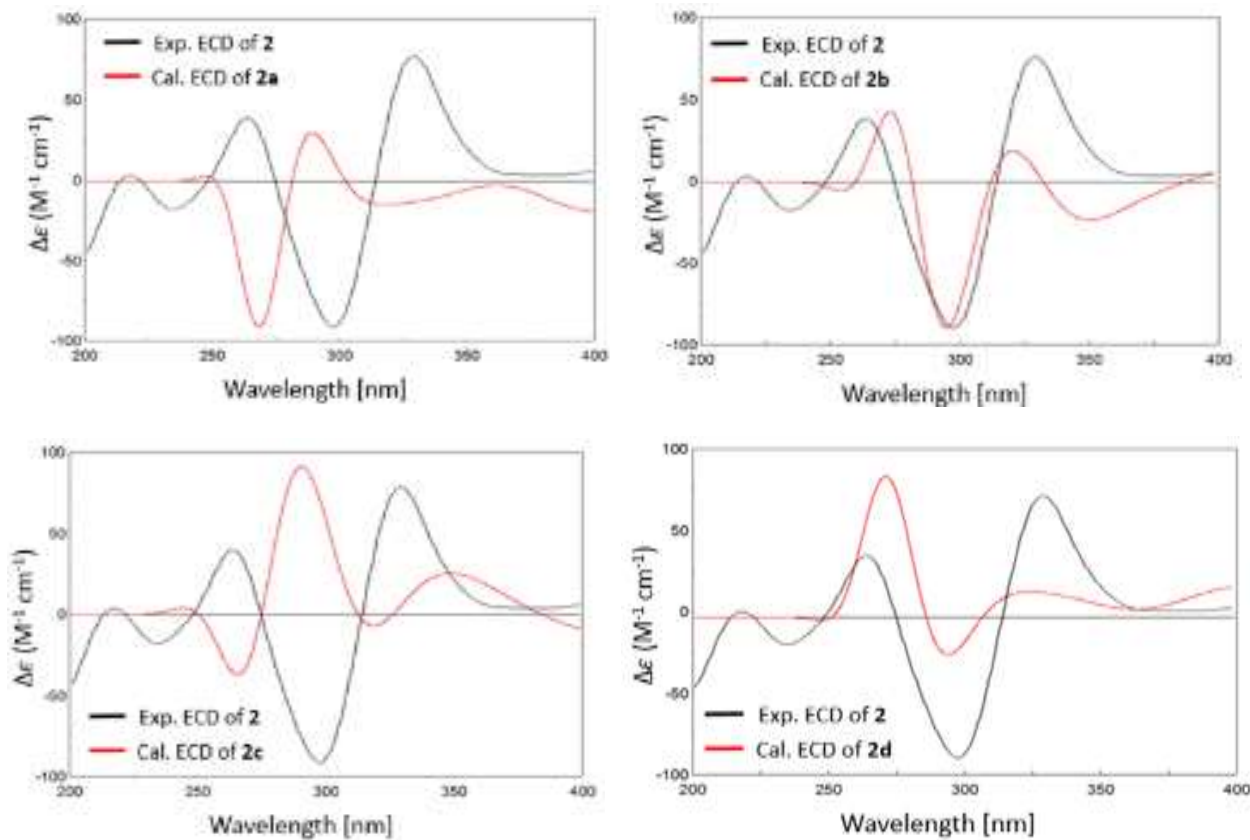

Figure S44. Comparison of experimental ECD spectrum of 4 with calculated ECD spectra of $(P$, $\left.3 S, 4 S, 3^{\prime} S, 4^{\prime} S\right)-\mathbf{4}(\mathbf{4 a})$ versus $\left(M, 3 S, 4 S, 3^{\prime} S, 4^{\prime} S\right)-\mathbf{4}(\mathbf{4 b})$ and $\left(P, 3 R, 4 R, 3^{\prime} R, 4^{\prime} R\right)-\mathbf{4}(\mathbf{4 c})$ versus $\left(M, 3 R, 4 R, 3^{\prime} R, 4^{\prime} R\right)-4(\mathbf{4 d})$.
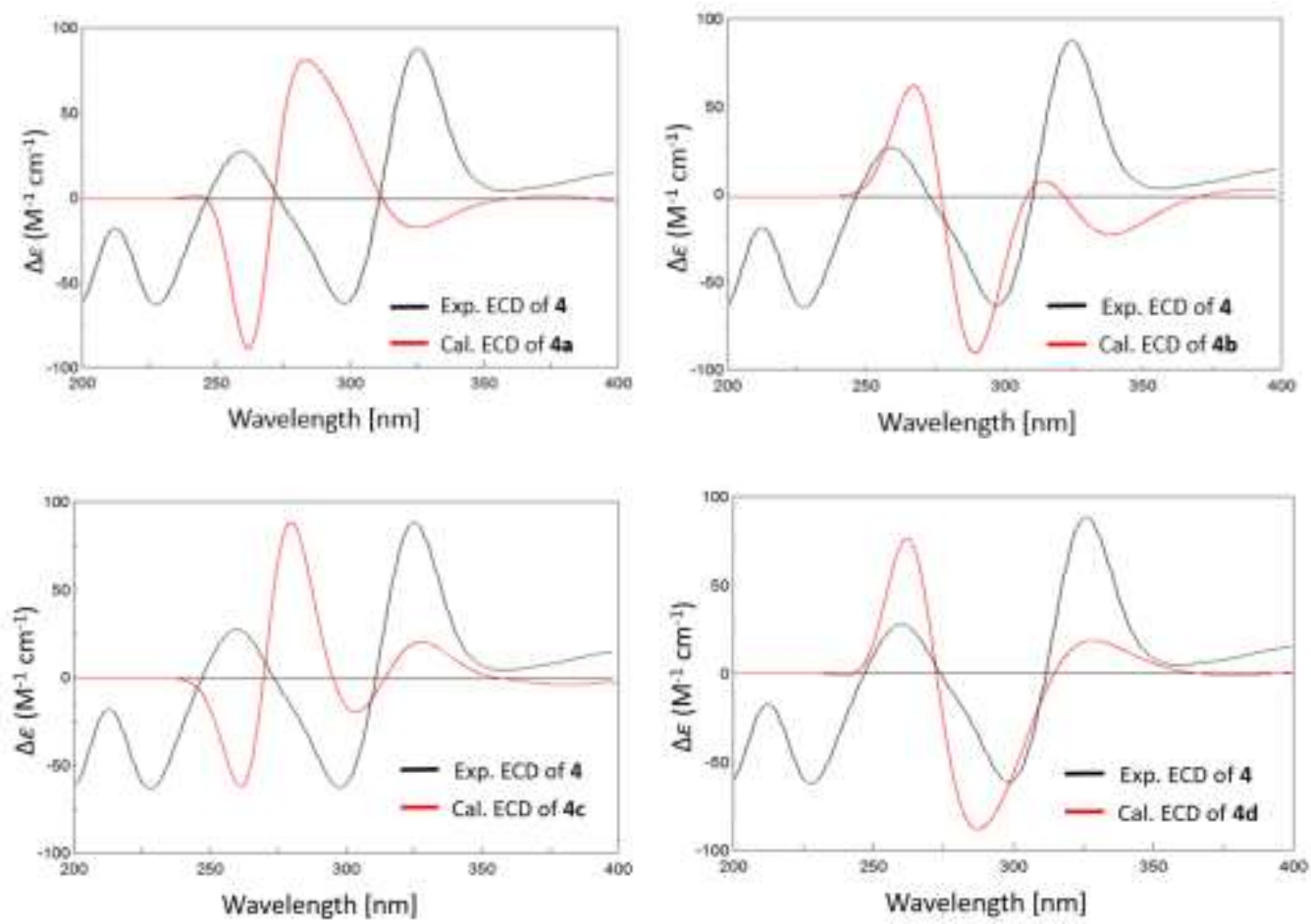
Figure S45. Comparison of experimental ECD spectrum of 5 with calculated ECD spectra of $(P$, $\left.3 S, 4 S, 3^{\prime} S, 4 ' S\right)-5$ (5a) versus $\left(M, 3 S, 4 S, 3^{\prime} S, 4 ' S\right)-5(\mathbf{5 b})$ and $\left(P, 3 R, 4 R, 3^{\prime} R, 4^{\prime} R\right)-5(\mathbf{5 c})$ versus $\left(M, 3 R, 4 R, 3^{\prime} R, 4^{\prime} R\right)-5(\mathbf{5 d})$.
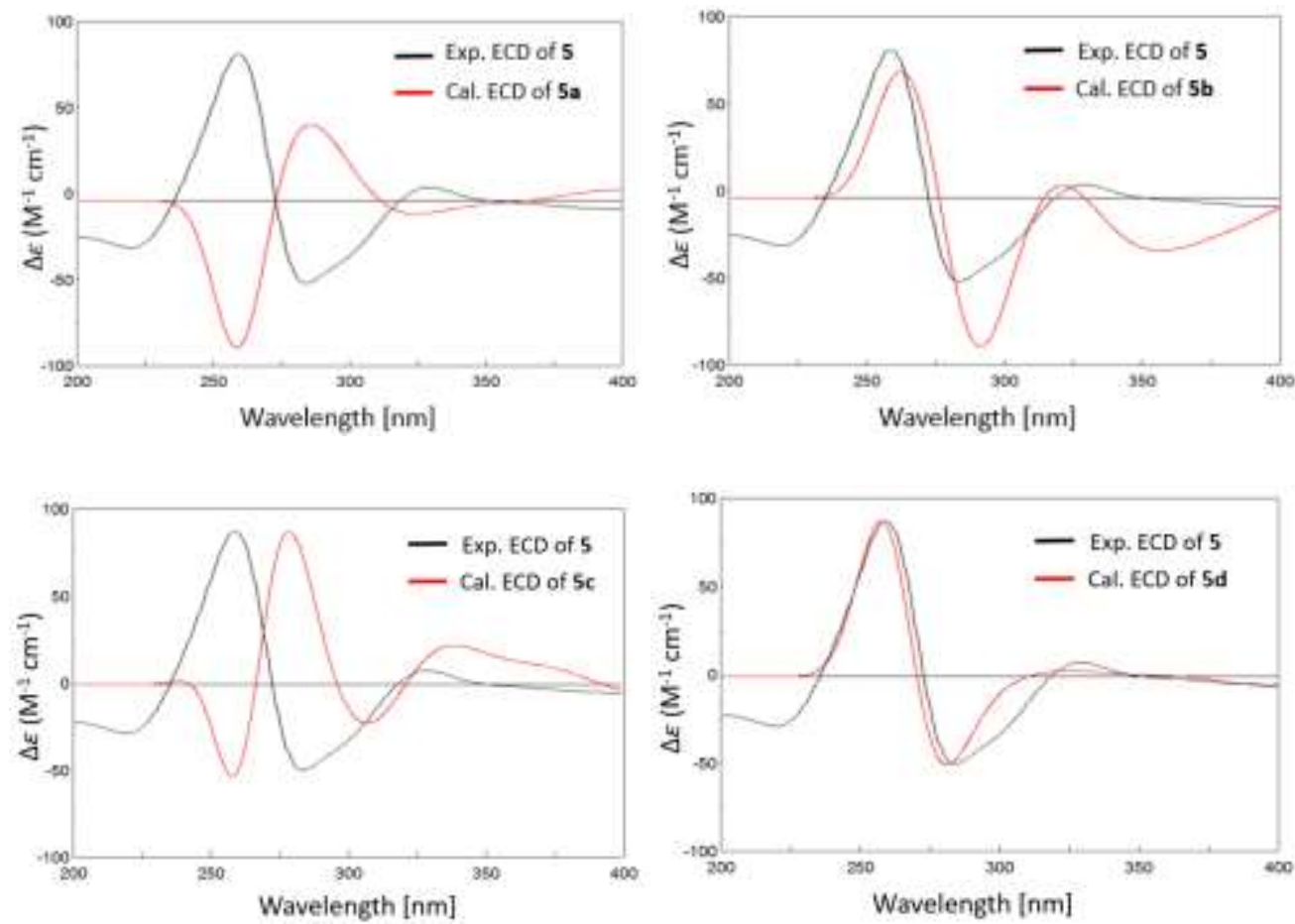

Figure S46. HPLC analysis ( $350 \mathrm{~nm}$ ) of compounds 1-5 from the crude of HDN10255.

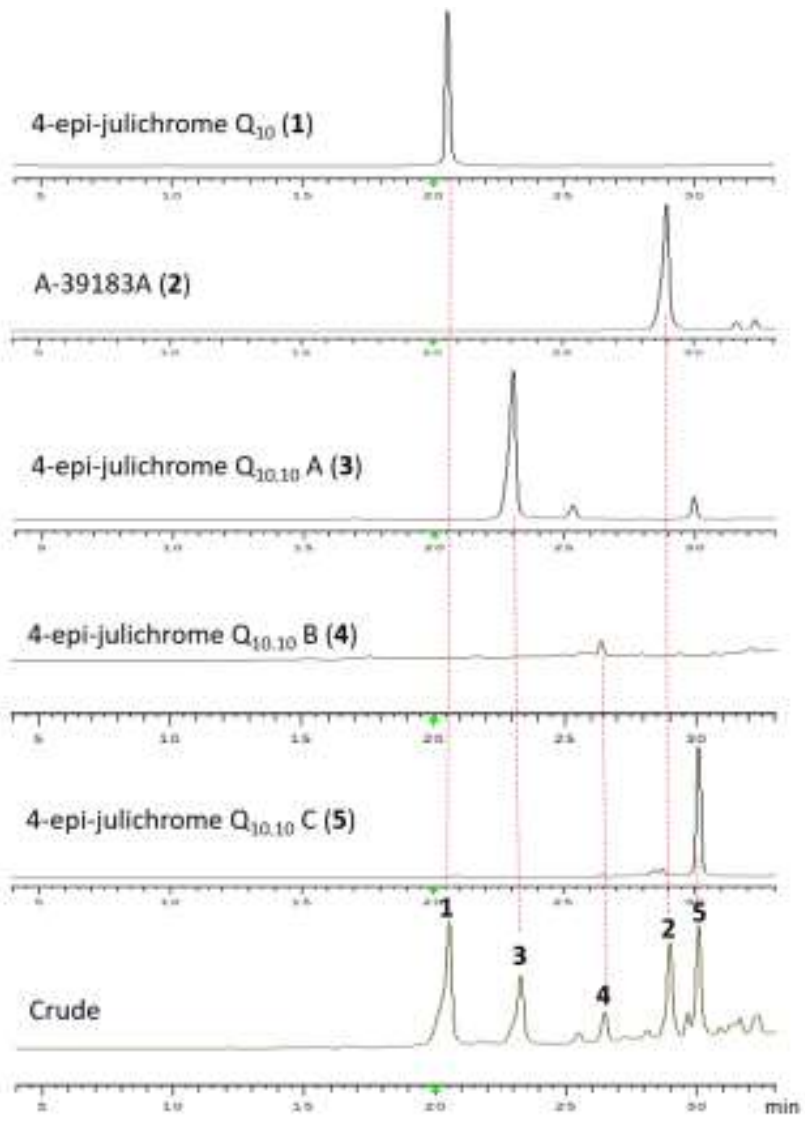


Figure S47. 16S rRNA gene sequence of HDN 10255.

CAAGTCGAACGATGAACCACTTCGGTGGGGATTAGTGGCGAACGGGTGAGTAACACG TGGGCAATCTGCCCTGCACTCTGGGACAAGCCCTGGAAACGGGGTCTAATACCGGAT ACAACCACTGACCGCATGGTCGGGTGGTGGAAAGCTCCGGCGGTGCAGGATGAGCCC GCGGCCTATCAGCTTGTTGGTGAGGTAACGGCTCACCAAGGCGACGACGGGTAGCCG GCCTGAGAGGGCGACCGGCCACACTGGGACTGAGACACGGCCCAGACTCCTACGGG AGGCAGCAGTGGGGAATATTGCACAATGGGCGAAAGCCTGATGCAGCGACGCCGCG TGAGGGATGACGGCCTTCGGGTTGTAAACCTCTTTCAGCAGGGAAGAAGCGAGAGTG ACGGTACCTGCAGAAGAAGCGCCGGCTAACTACGTGCCAGCAGCCGCGGTAATACGT AGGGCGCAAGCGTTGTCCGGAATTATTGGGCGTAAAGAGCTCGTAGGCGGCTTGTCA CGTCGGTTGTGAAAGCCCGGGGCTTAACCCCGGGTCTGCAGTCGATACGGGCAGGCT AGAGTTCGGTAGGGGAGATCGGAATTCCTGGTGTAGCGGTGAAATGCGCAGATATCA GGAGGAACACCGGTGGCGAAGGCGGATCTCTGGGCCGATACTGACGCTGAGGAGCG AAAGCGTGGGGAGCGAACAGGATTAGATACCCTGGTAGTCCACGCCGTAAACGGTGG GCACTAGGTGTGGGCGACATTCCACGTCGTCCGTGCCGCAGCTAACGCATTAAGTGC CCCGCCTGGGGAGTACGGCCGCAAGGCTAAAACTCAAAGGAATTGACGGGGGCCCG CACAAGCGGCGGAGCATGTGGCTTAATTCGACGCAACGCGAAGAACCTTACCAAGGC TTGACATACACCGGAAACGTCTGGAGACAGGCGCCCCCTTGTGGTCGGTGTACAGGT GGTGCATGGCTGTCGTCAGCTCGTGTCGTGAGATGTTGGGTTAAGTCCCGCAACGAGC GCAACCCTTGTCCCGTGTTGCCAGCAGGCCCTTGTGGTGCTGGGGACTCACGGGAGA CCGCCGGGGTCAACTCGGAGGAAGGTGGGGACGACGTCAAGTCATCATGCCCCTTAT GTCTTGGGCTGCACACGTGCTACAATGGCCGGTACAATGAGCTGCGATACCGTGAGG TGGAGCGAATCTCAAAAAGCCGGTCTCAGTTCGGATTGGGGTCTGCAACTCGACCCC ATGAAGTCGGAGTCGCTAGTAATCGCAGATCAGCATTGCTGCGGTGAATACGTTCCC GGGCCTTGTACACACCGCCCGTCACGTCACGAAAGTCGGTAACACCCGAAGCCGGTG GCCCAACCCCTT (Remove the primer, $1377 \mathrm{bp)}$ 
Figure S48. IR spectra of compounds 1-5

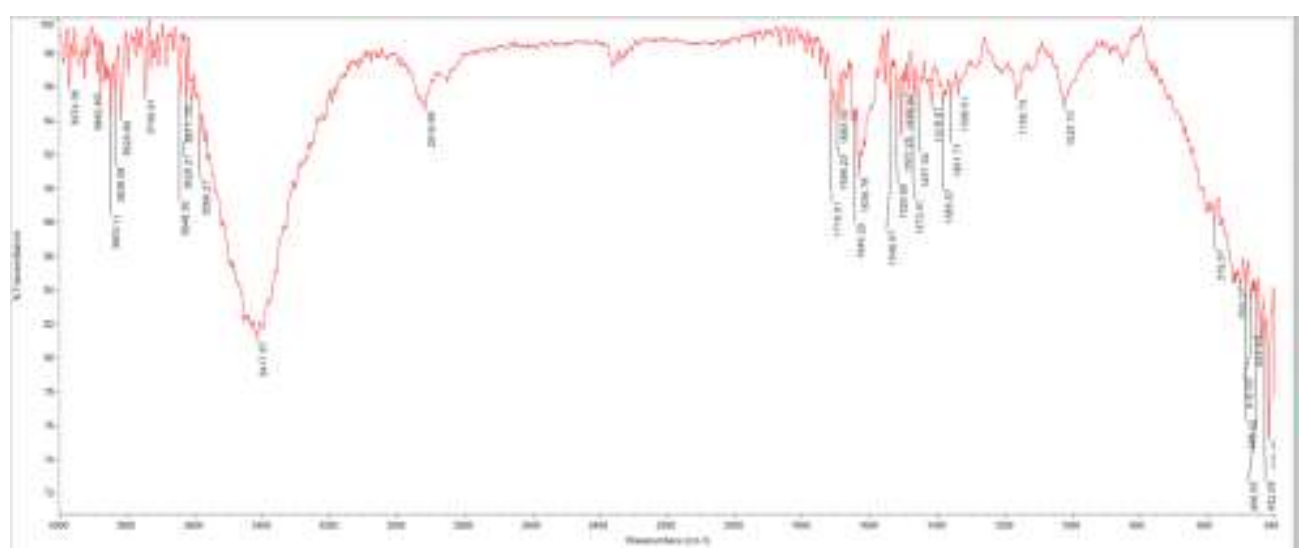

IR spectrum of compound $\mathbf{1}$

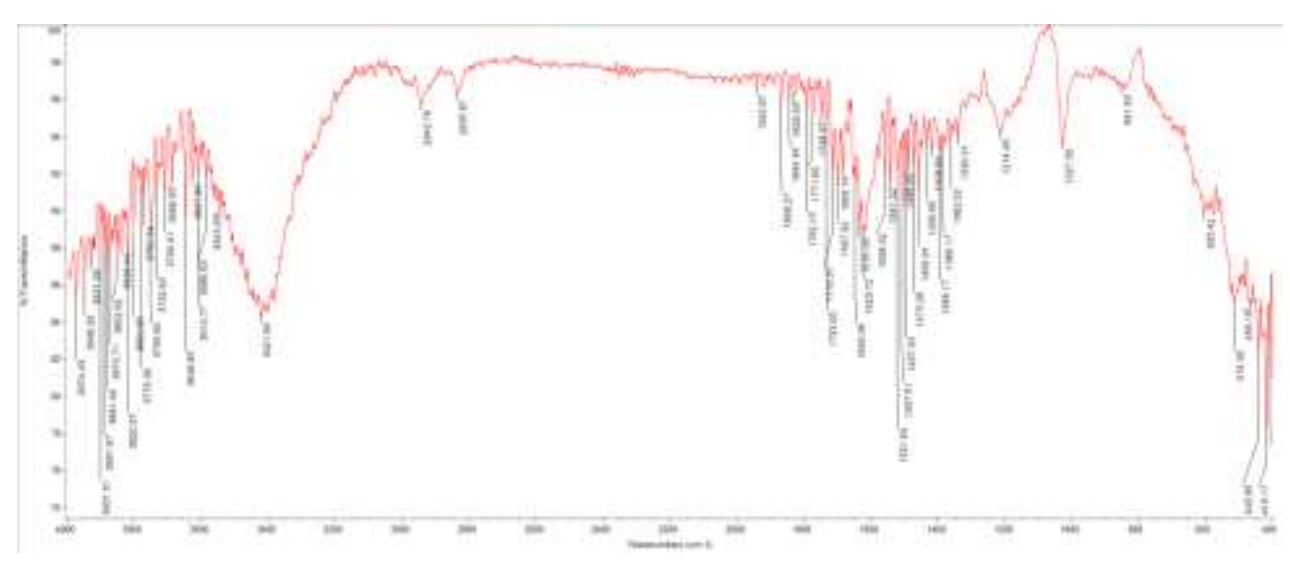

IR spectrum of compound $\mathbf{2}$

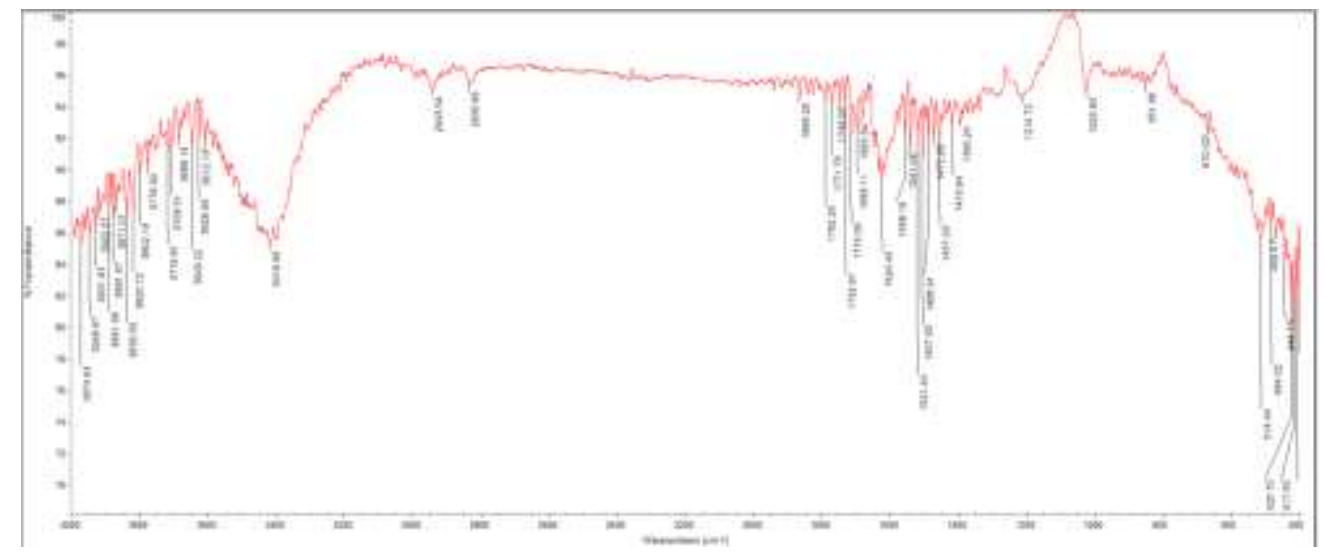

IR spectrum of compound $\mathbf{3}$ 


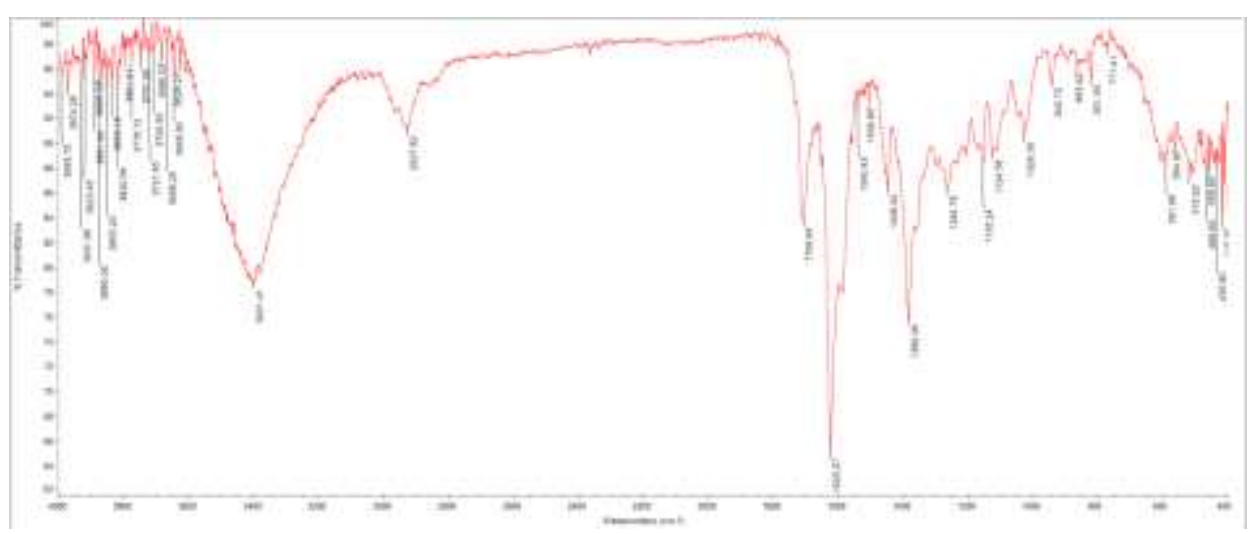

IR spectrum of compound 4

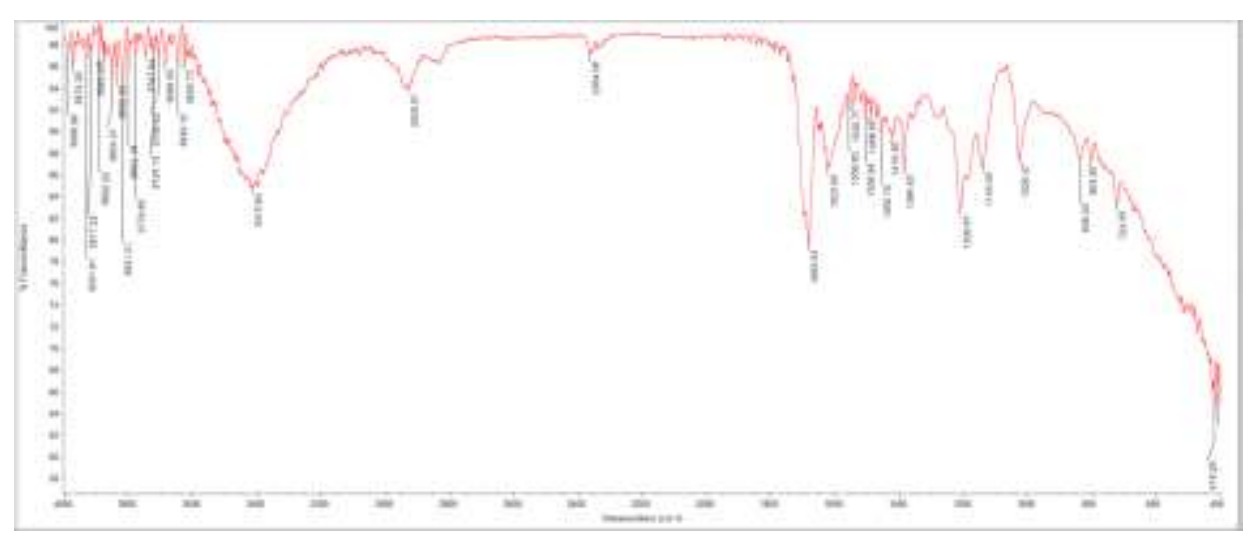

IR spectrum of compound 5

Table S1. Calculated and experimental values for ${ }^{1} \mathrm{H}$ NMR chemical of $\mathbf{1 a}$

\begin{tabular}{llllll}
\hline position & $\delta$ calcd. & $\delta$ exp. & Error & $\delta$ scalcd. & $\Delta \delta$ exp-scalc \\
\hline 2 & 2.68 & 2.71 & 0.03 & 2.86 & 0.15 \\
& 2.94 & 3.47 & 0.53 & 3.10 & 0.37 \\
$3-\mathrm{CH}_{3}$ & 1.32 & 1.45 & 0.13 & 1.61 & 0.16 \\
4 & 3.87 & 4.17 & 0.30 & 3.96 & 0.21 \\
5 & 7.34 & 7.13 & 0.21 & 7.15 & 0.02 \\
6 & 7.79 & 7.49 & 0.30 & 7.57 & 0.08 \\
7 & 7.33 & 6.86 & 0.47 & 7.14 & 0.28 \\
10 & 6.92 & 7.04 & 0.12 & 6.76 & 0.28 \\
12 & 2.36 & 2.39 & 0.03 & 2.56 & 0.17 \\
\hline
\end{tabular}


Table S2. Calculated and experimental values for ${ }^{1} \mathrm{H}$ NMR chemical of 1c

\begin{tabular}{llllll}
\hline position & $\delta$ calcd. & $\delta$ exp. & Error & $\delta$ scalcd. & $\Delta \delta$ exp-scalc \\
\hline \multirow{2}{*}{2} & 2.60 & 2.71 & 0.11 & 2.62 & 0.09 \\
$3-\mathrm{CH}_{3}$ & 1.28 & 1.45 & 0.17 & 1.38 & 0.07 \\
4 & 4.27 & 4.17 & 0.10 & 4.17 & 0.00 \\
5 & 7.36 & 7.13 & 0.23 & 7.06 & 0.07 \\
6 & 7.84 & 7.49 & 0.35 & 7.50 & 0.01 \\
7 & 7.13 & 6.86 & 0.27 & 6.84 & 0.02 \\
10 & 7.39 & 7.04 & 0.35 & 7.08 & 0.04 \\
12 & 2.48 & 2.39 & 0.09 & 2.50 & 0.11 \\
\hline
\end{tabular}

Table S3. Calculated and experimental values for ${ }^{13} \mathrm{C}$ NMR chemical of 1a

\begin{tabular}{lllll}
\hline position & $\delta$ calcd. & $\delta$ exp. & $\delta$ scalcd. & $\Delta \delta$ exp-scalc \\
\hline 1 & 209.6 & 202.5 & 199.8 & 2.6 \\
2 & 55.5 & 47.3 & 52.6 & -5.3 \\
3 & 79.5 & 72.0 & 75.5 & -3.6 \\
$3-\mathrm{CH}_{3}$ & 29.0 & 27.3 & 27.3 & 0.0 \\
4 & 68.9 & 62.8 & 65.4 & -2.6 \\
$4 \mathrm{a}$ & 138.4 & 131.9 & 131.8 & 0.1 \\
5 & 121.5 & 118.5 & 115.7 & 2.8 \\
6 & 141.8 & 133.1 & 135.1 & -2.0 \\
7 & 114.7 & 112.0 & 109.2 & 2.8 \\
8 & 166.9 & 158.1 & 159.1 & -1.0 \\
$8 \mathrm{a}$ & 115.7 & 113.2 & 110.2 & 3.1 \\
9 & 172.8 & 166.5 & 164.7 & 1.8 \\
$9 \mathrm{a}$ & 113.6 & 108.2 & 108.1 & 0.1 \\
10 & 122.0 & 119.3 & 116.2 & 3.1 \\
$10 \mathrm{a}$ & 145.0 & 138.9 & 138.2 & 0.8 \\
11 & 222.0 & 206.0 & 211.8 & -5.8 \\
12 & 30.9 & 32.1 & 29.0 & 3.0 \\
\hline
\end{tabular}


Table S4. Calculated and experimental values for ${ }^{13} \mathrm{C}$ NMR chemical of $1 \mathrm{c}$

\begin{tabular}{lllll}
\hline position & $\delta$ calcd. & $\delta$ exp. & $\delta$ scalcd. & $\Delta \delta$ exp-scalc \\
\hline 1 & 211.0 & 202.5 & 201.6 & 0.9 \\
2 & 49.7 & 47.3 & 47.6 & -0.3 \\
3 & 79.0 & 72.0 & 75.6 & -3.6 \\
$3-\mathrm{CH}_{3}$ & 27.2 & 27.3 & 26.2 & 1.1 \\
4 & 66.5 & 62.8 & 63.6 & -0.8 \\
$4 \mathrm{a}$ & 138.5 & 131.9 & 132.3 & -0.4 \\
5 & 121.1 & 118.5 & 115.8 & 2.6 \\
6 & 141.0 & 133.1 & 134.7 & -1.6 \\
7 & 114.9 & 112.0 & 109.8 & 2.2 \\
8 & 166.9 & 158.1 & 159.5 & -1.4 \\
$8 \mathrm{a}$ & 116.5 & 113.2 & 111.4 & 1.9 \\
9 & 173.5 & 166.5 & 165.8 & 0.7 \\
$9 \mathrm{a}$ & 111.8 & 108.2 & 106.9 & 1.3 \\
10 & 124.4 & 119.3 & 118.9 & 0.4 \\
$10 \mathrm{a}$ & 145.2 & 138.9 & 138.8 & 0.1 \\
11 & 217.7 & 206.0 & 207.9 & -1.9 \\
12 & 34.4 & 32.1 & 33.1 & -1.0 \\
\hline
\end{tabular}

Table S5-1. Comparison of main data between 1 and julichrome $\mathrm{Q}_{10}$.

\begin{tabular}{l|l|l}
\hline & \multicolumn{1}{|c|}{$\mathbf{1}$} & Julichrome Q \\
\hline Rotation & {$[\alpha]^{20} \mathrm{D}-30(\mathrm{c} 0.1, \mathrm{MeOH})$.} & {$[\alpha]^{25} \mathrm{D}-69.99(\mathrm{c} 0.1, \mathrm{MeOH})$.} \\
\hline ECD curve & $261(+), 298(-), 327(+) \mathrm{nm}$ & $269(+), 299(-), 313(+) \mathrm{nm}$ \\
\hline
\end{tabular}


Table S5-2. ${ }^{1} \mathrm{H}$ and ${ }^{13} \mathrm{C}$ NMR of 1 and julichrome $\mathrm{Q}_{10}(\delta$ ppm, $J$ in $\mathrm{Hz})$.

\begin{tabular}{|c|c|c|c|c|c|c|c|c|}
\hline \multirow[b]{2}{*}{ No. } & \multicolumn{2}{|c|}{$\begin{array}{c}1 \\
\left(\mathrm{CDCl}_{3},\right. \\
500 \mathrm{MHz})\end{array}$} & \multicolumn{2}{|c|}{$\begin{array}{c}\mathbf{1} \\
\text { (acetone- } d_{6}, \\
400 \mathrm{MHz}) \\
\end{array}$} & \multicolumn{2}{|c|}{$\begin{array}{c}\text { Julichrome } \mathrm{Q}_{10} \\
\text { (acetone- } d_{6} \\
500 \mathrm{MHz})\end{array}$} & \multicolumn{2}{|c|}{$\begin{array}{c}\text { Chemical shift } \\
\text { comparison in } \\
\text { actone- } d_{6} \\
\end{array}$} \\
\hline & $\delta_{\mathrm{H}}$ & $\delta_{\mathrm{C}}$ & $\delta_{\mathrm{H}}$ & $\delta_{\mathrm{C}}$ & $\delta_{\mathrm{H}}$ & $\delta_{\mathrm{C}}$ & $\Delta \delta_{\mathrm{H}}$ & $\Delta \delta_{\mathrm{C}}$ \\
\hline 1 & & 202.5 & & 205.5 & & 205.2 & & 0.3 \\
\hline \multirow{2}{*}{2} & 2.71, d (18.3) & 473 & $2.72, \mathrm{~d}(18.0)$ & 48.2 & $2.73, \mathrm{~d}(15.0)$ & 48.8 & -0.01 & -0.6 \\
\hline & 3.47, d (18.3) & 41.3 & $3.40, \mathrm{~d}(18.0)$ & & $3.30, \mathrm{~d}(15.0)$ & & 0.10 & \\
\hline 3 & & 72.0 & & 71.8 & & 72.3 & & -0.5 \\
\hline $3-\mathrm{CH}_{3}$ & $1.45, \mathrm{~s}$ & 27.3 & $1.48, \mathrm{~s}$ & 28.0 & $1.37, \mathrm{~s}$ & 31.3 & 0.11 & -3.3 \\
\hline $3-\mathrm{OH}$ & & & 4.83, br s & & $4.72, \mathrm{~s}$ & & 0.11 & \\
\hline 4 & $4.17, \mathrm{~s}$ & 62.8 & $4.46, \mathrm{~s}$ & 63.6 & $4.45, \mathrm{~s}$ & 62.9 & 0.01 & 0.7 \\
\hline $4 \mathrm{a}$ & & 131.9 & & 140.3 & & 140.2 & & 0.1 \\
\hline 5 & 7.13, d (7.7) & 118.5 & 7.31, d (7.9) & 119.4 & 7.25, d (7.6) & 119.4 & 0.06 & 0.0 \\
\hline 6 & $7.49, \mathrm{t}(7.7)$ & 133.1 & $7.55, \mathrm{t}(7.9)$ & 135.5 & $7.55, \mathrm{t}(7.6)$ & 135.7 & 0.00 & -0.2 \\
\hline 7 & $6.86, \mathrm{~d}(7.7)$ & 112.0 & $6.85, \mathrm{~d}(7.9)$ & 110.1 & $6.84, \mathrm{~d}(7.6)$ & 109.9 & 0.01 & 0.2 \\
\hline 8 & & 158.1 & & 159.0 & & 159.0 & & 0.0 \\
\hline $8-\mathrm{OH}$ & 9.69, br s & & & & & & & \\
\hline $8 \mathrm{a}$ & & 113.2 & & 113.7 & & 113.8 & & -0.1 \\
\hline 9 & & 166.5 & & 166.4 & & 166.5 & & -0.1 \\
\hline 9-OH & & & 9.74, br s & & $9.69, \mathrm{~s}$ & & 0.05 & \\
\hline $9 \mathrm{a}$ & & 108.2 & & 112.1 & & 112.1 & & 0.0 \\
\hline 10 & $7.04, \mathrm{~s}$ & 119.3 & $7.31, \mathrm{~s}$ & 119.4 & $7.22, \mathrm{~s}$ & 119.4 & 0.09 & 0.0 \\
\hline $10 \mathrm{a}$ & & 138.9 & & 133.6 & & 133.7 & & -0.1 \\
\hline 11 & & 206.0 & & 207.4 & & 208.4 & & -1.0 \\
\hline 12 & $2.39, \mathrm{~s}$ & 32.1 & $2.46, \mathrm{~s}$ & 32.7 & $2.42, \mathrm{~s}$ & 33.6 & 0.04 & -0.9 \\
\hline
\end{tabular}

